\title{
Validation of middle-atmospheric campaign-based water vapour measured by the ground-based microwave radiometer MIAWARA-C
}

\author{
B. Tschanz ${ }^{1,2}$, C. Straub ${ }^{3}$, D. Scheiben ${ }^{1,2}$, K. A. Walker ${ }^{4}$, G. P. Stiller ${ }^{5}$, and N. Kämpfer ${ }^{1,2}$ \\ ${ }^{1}$ Institute of Applied Physics, University of Bern, Bern, Switzerland \\ ${ }^{2}$ Oeschger Centre for Climate Change Research, University of Bern, Bern, Switzerland \\ ${ }^{3}$ Norwegian University of Science and Technology, Trondheim, Norway \\ ${ }^{4}$ Department of Physics, University of Toronto, Toronto, Canada \\ ${ }^{5}$ Karlsruhe Institute of Technology, Institute for Meteorology and Climate Research, Karlsruhe, Germany \\ Correspondence to: B. Tschanz (brigitte.tschanz@iap.unibe.ch)
}

Received: 18 January 2013 - Published in Atmos. Meas. Tech. Discuss.: 6 February 2013

Revised: 15 June 2013 - Accepted: 20 June 2013 - Published: 23 July 2013

\begin{abstract}
Middle atmospheric water vapour can be used as a tracer for dynamical processes. It is mainly measured by satellite instruments and ground-based microwave radiometers. Ground-based instruments capable of measuring middle-atmospheric water vapour are sparse but valuable as they complement satellite measurements, are relatively easy to maintain and have a long lifetime. MIAWARA-C is a ground-based microwave radiometer for middle-atmospheric water vapour designed for use on measurement campaigns for both atmospheric case studies and instrument intercomparisons. MIAWARA-C's retrieval version 1.1 (v1.1) is set up in a such way as to provide a consistent data set even if the instrument is operated from different locations on a campaign basis. The sensitive altitude range for v1.1 extends from $4 \mathrm{hPa}(37 \mathrm{~km})$ to $0.017 \mathrm{hPa}(75 \mathrm{~km})$. For v1.1 the estimated systematic error is approximately $10 \%$ for all altitudes. At lower altitudes it is dominated by uncertainties in the calibration, with altitude the influence of spectroscopic and temperature uncertainties increases. The estimated random error increases with altitude from 5 to $25 \%$. MIAWARA-C measures two polarisations of the incident radiation in separate receiver channels, and can therefore provide two measurements of the same air mass with independent instrumental noise. The standard deviation of the difference between the profiles obtained from the two polarisations is in excellent agreement with the estimated random measurement error of v1.1. In this paper, the quality of v1.1 data
\end{abstract}

is assessed for measurements obtained at two different locations: (1) a total of 25 months of measurements in the Arctic (Sodankylä, $67.37^{\circ} \mathrm{N}, 26.63^{\circ} \mathrm{E}$ ) and (2) nine months of measurements at mid-latitudes (Zimmerwald, $46.88^{\circ} \mathrm{N}, 7.46^{\circ} \mathrm{E}$ ). For both locations MIAWARA-C's profiles are compared to measurements from the satellite experiments Aura MLS and MIPAS. In addition, comparisons to ACE-FTS and SOFIE are presented for the Arctic and to the ground-based radiometer MIAWARA for the mid-latitude campaigns. In general, all intercomparisons show high correlation coefficients, confirming the ability of MIAWARA-C to monitor temporal variations of the order of days. The biases are generally below $13 \%$ and within the estimated systematic uncertainty of MIAWARA-C. No consistent wet or dry bias is identified for MIAWARA-C. In addition, comparisons to the reference instruments indicate the estimated random error of v1.1 to be a realistic measure of the random variation on the retrieved profile between 45 and $70 \mathrm{~km}$.

\section{Introduction}

Water vapour is a trace gas that plays a major role in radiative, chemical and heterogeneous processes in the atmosphere. It enters the stratosphere mainly through the tropical transition layer. Due to the cold tropopause temperatures in the tropics, dry freezing takes place, resulting in 
an extremely dry lower stratosphere. The second source of middle-atmospheric water vapour is the oxidation of methane leading to a positive vertical gradient in volume mixing ratio (VMR) throughout the stratosphere. The increasing photodissociation with altitude results in a negative gradient in the mesosphere. The latitudinal distribution of water vapour in the middle atmosphere is mainly given by the large-scale residual circulation.

The chemical lifetime of water vapour is of the order of months in the stratosphere and decreases to weeks in the mesosphere (Brasseur et al., 1999). Because of its chemical stability, water vapour can be used as a tracer for dynamics wherever horizontal or vertical gradients exist. For recent studies using water vapour as a tracer, see e.g. Lossow et al. (2009), Lee et al. (2011), Straub et al. (2012) or Scheiben et al. (2012).

Middle atmospheric water vapour is mainly measured by satellite instruments using infrared or microwave radiation and ground-based microwave radiometers. Satellite measurements offer good global coverage and good vertical resolution depending on the measurement technique but include horizontal averaging. Ground-based microwave instruments for water vapour deliver vertical profiles above the measurement site with high temporal but coarse vertical resolution.

There are several microwave radiometers for middleatmospheric water vapour currently in operation on a regular basis. Recent validation efforts (e.g. Haefele et al., 2009; Nedoluha et al., 2011; Straub et al., 2011) have demonstrated the reliability of this technique. Validation studies are an important tool to assess the data quality of an instrument. In addition to the identification of a possible bias, it is important to validate error estimates. The availability of realistic random uncertainty estimates is crucial for determining the significance of atmospheric studies.

This paper presents a validation of water vapour measured by the ground-based Middle Atmospheric Water Vapour Radiometer for Campaigns (MIAWARA-C). MIAWARA-C is a transportable instrument and has proven to provide reliable measurements. It is planned to operate MIAWARA-C within the Network for the Detection of Atmospheric Composition Change (NDACC) as a travelling standard. Therefore, the quality of the measured water vapour profiles is assessed in this study. The validation is based on results from the Lapland Atmosphere-Biosphere Facility (LAPBIAT, Sodankylä) campaign from January to June 2010 in polar latitudes, from Zimmerwald, a mid-latitude station near Bern, from July 2010 to May 2011 and from Sodankylä from June 2011 to February 2013. Reference data from another ground-based microwave instrument, MIAWARA, as well as satellite data from the Atmospheric Chemistry Experiment Fourier Transform Spectrometer (ACE-FTS), the Solar Occultation For Ice Experiment (SOFIE), the Michelson Interferometer for Passive Atmospheric Sounding (MIPAS) and from the Aura Microwave Limb Sounder (MLS) are used.
The article is organised as follows. In Sect. 2 the characteristics of MIAWARA-C and its retrieval are presented. The different reference instruments are described in Sect. 3, including results from previous water vapour intercomparison studies. After introducing the coincident data sets and the method of intercomparison (Sect. 4) the results are presented in Sect. 5. Section 6 summarises the results and Sect. 7 draws conclusions.

\section{MIAWARA-C}

The ground-based microwave radiometer MIAWARA-C measures the rotational emission line of water vapour at 22.235 GHz. The pressure broadening of this spectral line allows vertical water vapour profiles in the middle atmosphere to be retrieved. A detailed description of the instrument can be found in Straub et al. (2010).

\subsection{Instrument}

MIAWARA-C is a compact radiometer equipped with its own weather station, and is designed for use in measurement campaigns. The whole instrument, front end, back end and computer, is placed in the same housing with a rain hood that closes automatically in order to prevent damage to the instrument whenever there is precipitation or strong winds. In order to operate MIAWARA-C, the instrument is just connected to power and the Internet and can then be controlled remotely. The calibration does not depend on any other instrument nor on liquid nitrogen and therefore does not require intervention of an on-site operator. MIAWARA-C's optical system consists of a very compact choked Gaussian horn antenna and a parabolic off-axis mirror. It has a total length of approximately $50 \mathrm{~cm}$, which is very short in comparison to other $22 \mathrm{GHz}$ radiometers.

The receiver of MIAWARA-C consists of two identical receiver chains separated immediately after the antenna. Originally, the receiver was used as a correlation receiver with a noise source as internal calibration load and a digital cross correlating spectrometer for data acquisition. In December 2010 there was a major upgrade of the receiver of MIAWARA-C: the correlation receiver was replaced by a dual-polarisation receiver as shown in Fig. 1. In this new setup the incident radiation is split into vertical and horizontal polarisation by an orthomode transducer (OMT) placed immediately after the antenna. The two polarised signals are processed in the two identical receiver chains and separately analysed in the digital fast Fourier transform (FFT) spectrometer with a spectral resolution of $30.5 \mathrm{kHz}$ and a usable bandwidth of $400 \mathrm{MHz}$.

In order to calibrate the measurements, a balancing scheme is applied consisting of a reference measurement of the sky at zenith with a microwave absorber inserted and a line measurement at a low elevation angle $\left(10\right.$ to $\left.18^{\circ}\right)$. The 


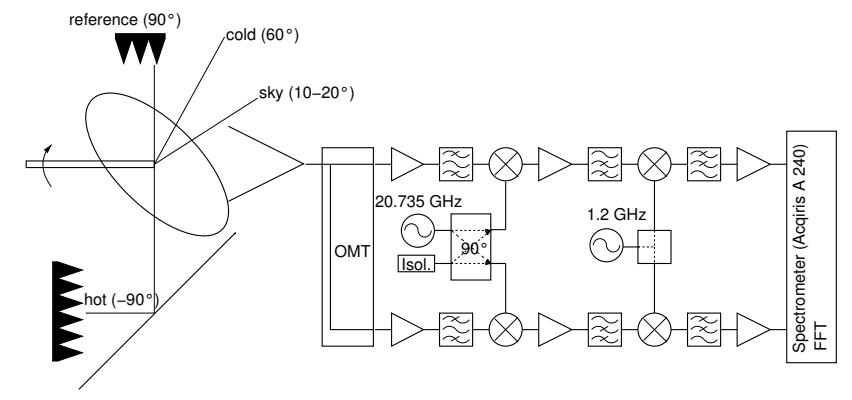

Fig. 1. Dual-polarisation receiver of MIAWARA-C after December 2010. The signal is split by the orthomode transducer and analysed using two separate receiver chains.

elevation angle of the line measurement is continuously adjusted to balance the reference measurement. For the absolute calibration two black body targets are measured: a microwave absorber at ambient temperature used as the hot load and the sky at an elevation angle of $60^{\circ}$ representing the cold load. The brightness temperature of the cold load is determined with regular tipping curve measurements. For details, see Straub et al. (2010).

The difference measurements, line minus reference, are calibrated and corrected for tropospheric attenuation resulting in spectra $\boldsymbol{y}$ as seen from the tropopause in zenith direction. For the profile retrieval a number of measured spectra need to be averaged in order to achieve a sufficiently high signal-to-noise ratio. For MIAWARA-C, spectra are averaged until a noise level of $0.014 \mathrm{~K}$ is reached. Averaging to a fixed noise level results in data covering an almost constant altitude range. The temporal resolution of the integrated spectra used for the profile retrieval mainly depends on the tropospheric opacity and on the observation geometry (Straub et al., 2011).

The two signals measured by the two receiver chains of the dual-polarisation receiver are calibrated separately. The two measurements, $\boldsymbol{y}_{1}$ and $\boldsymbol{y}_{2}$, with noise levels $\sigma_{1}$ and $\sigma_{2}$, share the same optical system, and can therefore be either regarded as two independent measurements of the same air mass or they can be combined into one spectrum which has the advantage of lower measurement noise. Both polarised spectra are weighted according to their variance to obtain the combined spectrum, $\boldsymbol{y}$ :

$\boldsymbol{y}=\frac{\sigma_{2}^{2} \boldsymbol{y}_{1}+\sigma_{1}^{2} \boldsymbol{y}_{2}}{\sigma_{1}^{2}+\sigma_{2}^{2}}$.

MIAWARA-C and its calibration scheme have gradually been improved to increase the temporal resolution. The upgrade to the dual-polarisation receiver reduced the integration time by a factor of 4 compared to the correlation receiver, allowing more than one profile per hour to be retrieved under favourable tropospheric conditions when using the combined spectrum. The number of profiles per day obtained by MIAWARA-C is presented in Fig. 2. With the
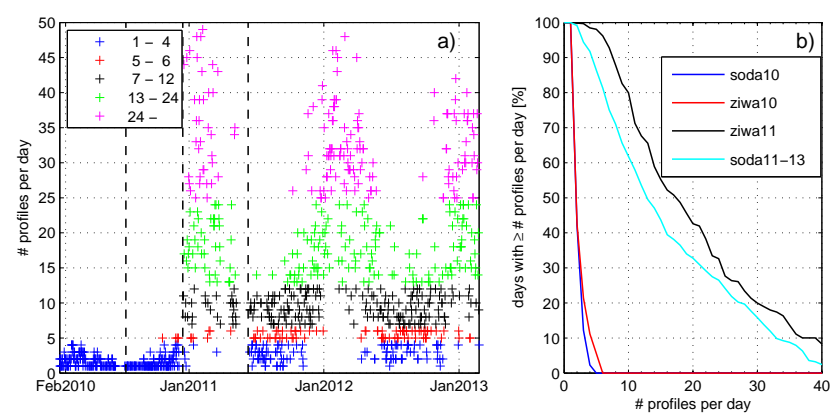

Fig. 2. Left: number of profiles obtained per day for the whole data set used for the validation study with a noise level of $0.014 \mathrm{~K}$ from MIAWARA-C. The increase in December 2010 is due to the replacement of the correlation receiver by the dual-polarisation receiver. The black dashed vertical lines indicate the beginning of a new comparison period. Right: percentage of days with $\geq \#$ profiles per day.

correlation receiver it was not possible to get more than five profiles per day, whereas with the dual-polarisation receiver more than 10 profiles are obtained on $80 \%$ of the measurement days, and hourly retrievals are possible on more than $30 \%$ of the days for Zimmerwald. The data measured with the new receiver for Zimmerwald were mainly obtained during winter months when the troposphere is drier. For more humid conditions, the integration time is slightly increased; for example, measurements from Sodankylä during the humid summer months of June to August in 2011 show that it is still possible to retrieve 10 or more profiles on $40 \%$ of all measurement days. Such a high temporal resolution above one location cannot be achieved by current satellite instruments. The good temporal resolution and its reliability are the major benefits of MIAWARA-C.

\subsection{Profile retrieval and auxiliary data}

The inversion, retrieving an altitude profile from the measured spectrum, is based on optimal estimation theory including a priori knowledge on the vertical water vapour profile distribution and is described in Rodgers (2000). For the retrieval, the Atmospheric Radiative Transfer Simulator (ARTS) is used as a forward model together with the software package Qpack (Buehler et al., 2005; Eriksson et al., 2005, 2011). A general description of the profile retrieval for MIAWARA-C can be found in Straub et al. (2010).

Ground-based microwave radiometers can be used to retrieve middle-atmospheric water vapour profiles over a limited altitude range. This altitude range is mainly given by a combination of the altitude-dependent shape of the pressure broadened line and the frequency resolution, bandwidth and spectral baseline of the instrument. The spectral baseline summarises all contributions to the spectrum not covered by the forward model (mainly standing waves, frequency dependency caused by the balancing calibration scheme and 
frequency dependence of the antenna pattern). Outside of the sensitive range the retrieved profile $\hat{\boldsymbol{x}}$ is approaching the a priori profile $\boldsymbol{x}_{\mathrm{a}}$. The relationship between true profile $(\boldsymbol{x})$, $\boldsymbol{x}_{\mathrm{a}}$ and $\hat{\boldsymbol{x}}$ is given by the averaging kernel matrix $\mathbf{A}$ :

$\hat{\boldsymbol{x}}=\mathbf{A} \boldsymbol{x}+(\mathbf{I}-\mathbf{A}) \boldsymbol{x}_{\mathrm{a}}+D_{y} \boldsymbol{\epsilon}$,

where $D_{y}=\frac{\partial \hat{x}}{\partial y}$ is the contribution function and describes the sensitivity of the retrieved profile to the measurement, $\boldsymbol{y}$, and $\boldsymbol{\epsilon}$ is the noise on the spectrum. The maximum a posteriori solution is given by

$\hat{\boldsymbol{x}}=\boldsymbol{x}_{\mathrm{a}}+\mathbf{S}_{\mathrm{a}} \mathbf{K}^{T}\left(\mathbf{K S}_{\mathrm{a}} \mathbf{K}^{T}+\mathbf{S}_{\epsilon}\right)^{-1}\left(\boldsymbol{y}-\mathbf{K} \boldsymbol{x}_{\mathrm{a}}\right)$,

where $\mathbf{S}_{\mathrm{a}}$ is the a priori covariance matrix, $\mathbf{K}=\frac{\partial \boldsymbol{y}}{\partial \boldsymbol{x}}$ the Jacobian of the forward model and $\mathbf{S}_{\epsilon}$ the covariance matrix of the spectral noise. In addition to the a priori statistics of water vapour, several auxiliary parameters used in the forward model need to be specified.

The aim of this study was to set up a retrieval version that is consistent for both receivers (the correlation and the dual-polarisation receiver) and for all past campaigns of MIAWARA-C. The retrieval version v1.1, whose specifications are presented below, fulfils these requirements. Depending on the application (e.g. case studies of dynamical events), other retrieval versions might be favourable.

The a priori profile information $\boldsymbol{x}_{\mathrm{a}}$ is taken from a monthly mean zonal mean climatology using Aura MLS version 2.2 (v2.2) data from 2004 to 2008. Aura MLS v2.2 covers the whole altitude range of MIAWARA-C and is available for all campaign sites. The monthly climatology is interpolated linearly to the day of the measurement to avoid discontinuities. The a priori covariance matrix used, $\mathbf{S}_{\mathrm{a}}$, has fixed VMR values, and the square root of its diagonal elements are shown in Fig. 3a. The a priori standard deviation increases from 0.72 parts per million by volume (ppmv) at $3.8 \mathrm{hPa}$ to $1.8 \mathrm{ppmv}$ at $0.017 \mathrm{hPa}$. In addition to the diagonal elements, the shape of $\mathbf{S}_{\mathrm{a}}$ is defined as exponentially decreasing towards the offdiagonal elements with a correlation length of $4 \mathrm{~km}$.

For the forward model calculations, a temperature profile is needed. For consistency of v1.1 the temperature profiles should be available for all of MIAWARA-C's past campaign sites. Therefore, temperature profiles together with pressure and geopotential height information from Aura MLS version 3.3 (v3.3) are used. A mean value of all temperature profiles with a maximal longitudinal distance of $800 \mathrm{~km}$, a maximal latitudinal distance of $400 \mathrm{~km}$ from the measurement site and within two days of the measurement time is used. MLS v3.3 temperatures have vertical/horizontal resolution of $7 \mathrm{~km} / 165 \mathrm{~km}$ at $1 \mathrm{hPa}$ and $8-12 \mathrm{~km} / 185 \mathrm{~km}$ at $0.01 \mathrm{hPa}$ and a precision of $1 \mathrm{~K}$ at $1 \mathrm{hPa}$ and $2.2 \mathrm{~K}$ at $0.01 \mathrm{hPa}$ (Livesey et al., 2011).

The line parameters used for the forward model are based on Poynter and Pickett (1985) and the broadening parameters are taken from Liebe (1989). In addition, the hyperfine
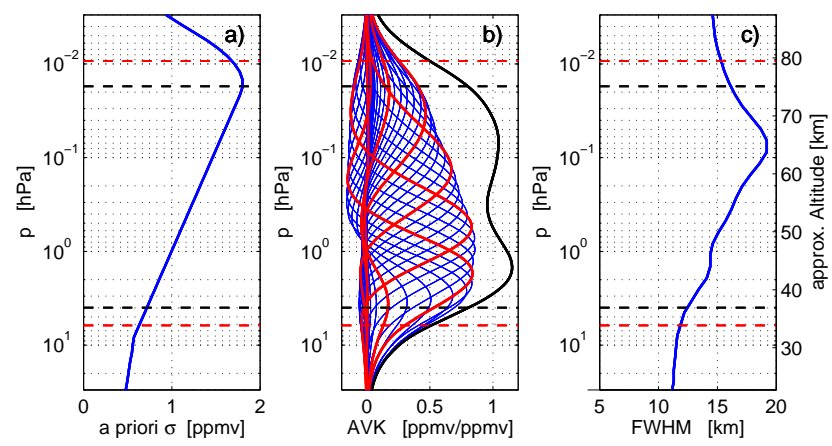

Fig. 3. (a) A priori standard deviation used for both MIAWARA-C and MIAWARA (square root of diagonal elements of $\mathbf{S}_{\mathrm{a}}$ ). (b) Averaging kernels multiplied by 5 for MIAWARA-C with a noise level of $0.014 \mathrm{~K}$ (blue); highlighted in red are the averaging kernel belonging to approximately $30,40,50,60,70$ and $80 \mathrm{~km}$. The black line shows the area of the averaging kernels (AoA) used as a measure for the sensitive altitude range of this retrieval version. (c) FWHM of the averaging kernel as a measure of vertical resolution. The red and black dashed lines indicate the altitude range with AoA $>0.5$ and AoA $>0.8$, respectively. AoA $>0.8$ is used as an upper and lower limit of this retrieval version.

splitting of the $22 \mathrm{GHz}$ line is taken into account. Due to the frequency resolution of the spectrometer of MIAWARA-C $(30.5 \mathrm{kHz})$, not all split lines are in the range of a single channel. The intensity is divided into the three frequencies with the highest branching ratios. The sum of the branching ratio of these three lines is larger than $99 \%$ (Seele, 1999). Specifications of the line parameters are presented in Table 1.

The forward model only includes the atmosphere as seen by a perfectly described instrument. The spectral baseline is removed by allowing the optimal estimation to fit a polynomial. For MIAWARA-C v1.1, a spectrum with $80 \mathrm{MHz}$ bandwidth and a polynomial fit of degree 2 is used.

The averaging kernels for a typical MIAWARA-C v1.1 retrieval are shown in Fig. 3b. For MIAWARA-C we define the reliable range of the retrieval as the region with the area of the averaging kernel (AoA) larger than 0.8. Outside of this range, the amplitude of the averaging kernel starts to shrink. In addition, the difference between the peak height of the averaging kernels and their nominal altitude (the altitude the averaging kernel is calculated for) increases, revealing not only an increase in a priori contribution but also the loss of altitude-dependent information. For the intercomparison presented here, MIAWARA-C's data are shown in the altitude range with $\mathrm{AoA}>0.5$, and the reliable altitude range with AoA $>0.8$ is marked with horizontal dashed lines in the relevant figures.

An estimation of the vertical resolution is obtained from the full width at half maximum (FWHM) of the averaging kernels. This estimate, presented in Fig. 3c, shows that the vertical resolution changes with altitude from $12 \mathrm{~km}$ to a maximum of $19 \mathrm{~km}$. The horizontal resolution is given by the 
Table 1. Spectroscopic parameters of the $6_{16}-5_{23}$ transition of water vapour for $T=300 \mathrm{~K}$ including hyperfine splitting ( $v_{0}$ is resonant frequency; $S$, line intensity; $E^{\prime \prime}$, lower state energy; $\gamma_{\text {air }}$, air broadening parameter; $n_{\text {air }}$, temperature dependence of $\gamma_{\text {air }} ; \gamma_{\text {self }}$, self broadening parameter; and $n_{\text {self }}$, temperature dependence of $\left.\gamma_{\text {self }}\right)$. The source of the single-line parameter is given in the header, the splitting of the intensity into three lines follows Seele (1999).

\begin{tabular}{lllllll}
\hline$\nu_{0}[\mathrm{GHz}]^{\mathrm{a}}$ & $S\left[\mathrm{~m}^{2} \mathrm{~Hz}\right]^{\mathrm{a}, \mathrm{b}}$ & $E^{\prime \prime}[\mathrm{J}]^{\mathrm{b}}$ & $\gamma_{\text {air }}\left[\mathrm{HzPa}^{-1}\right]^{\mathrm{c}}$ & $n_{\text {air }}{ }^{\mathrm{c}}$ & $\gamma_{\text {self }}\left[\mathrm{HzPa}^{-1}\right]^{\mathrm{c}}$ & $n_{\text {self }}{ }^{\mathrm{c}}$ \\
\hline 22.235043990 & $5.0257 \times 10^{-19}$ & $8.86987 \times 10^{-21}$ & 28110 & 0.69 & 134928 & 1 \\
22.235077056 & $4.2817 \times 10^{-19}$ & $8.86987 \times 10^{-21}$ & 28110 & 0.69 & 134928 & 1 \\
22.235120358 & $3.7229 \times 10^{-19}$ & $8.86987 \times 10^{-21}$ & 28110 & 0.69 & 134928 & 1 \\
\hline
\end{tabular}

${ }^{\mathrm{a}}$ Seele (1999), ${ }^{\mathrm{b}}$ Poynter and Pickett (1985), ${ }^{\mathrm{c}}$ Liebe (1989).

antenna pattern. The half-power beam width of $5^{\circ}$ at typical elevation angles of $17.5^{\circ}\left(12.5^{\circ}\right)$ leads to a horizontal resolution of approximately $40(77) \mathrm{km}$ at $40 \mathrm{~km}$ and $70(135) \mathrm{km}$ at $70 \mathrm{~km}$.

An example of a retrieval for MIAWARA-C for 21 March 2010 is illustrated in Fig. 4. Panel a shows the retrieved water vapour profile, which deviates considerably from the climatological state used as the a priori profile. In addition to the profiles, Fig. 4 presents the measured and fitted spectra in panel $\mathrm{b}$ as well as the residuals in panel $\mathrm{c}$. By using a bandwidth of $80 \mathrm{MHz}$ and allowing a polynomial fit of degree 2, no relevant baseline remains that could lead to unphysical oscillations in the retrieved profile.

\subsection{Error characterisation}

The error estimation for MIAWARA-C's profiles is based on Rodgers (2000) and performed using the software package Qpack. Thorough discussions of the error characterisation for $22 \mathrm{GHz}$ radiometers are presented in Straub et al. (2010) and De Wachter et al. (2011). A posteriori covariance matrices are calculated for different families of uncertainty, namely measurement noise, calibration, spectroscopic parameters and temperatures used in the forward model. The smoothing error can be ignored as long as the profiles to be compared have a similar vertical resolution. The a posteriori covariance matrices are determined by the a priori covariance matrices of the different quantities and their influence on the forward model, and also by the a priori covariance matrix $\mathbf{S}_{\mathrm{a}}$. Therefore, the estimated error depends on the choice of $\mathbf{S}_{\mathrm{a}}$. MIAWARA-C v1.1 uses a $\mathbf{S}_{\mathrm{a}}$ defined in VMR, resulting in error estimations approximately constant in VMR.

The uncertainties calculated for MIAWARA-C v1.1, based on the uncertainty estimates of the forward model parameters presented in Table 2, are displayed in Fig. 5. They are separated into two categories: random error and systematic error. The random error is the 1- $\sigma$ uncertainty determined as the root-mean-square error of contributions from propagation of the noise on the measured spectrum, random uncertainties in the temperature profiles and in the calibration. As a systematic error estimation the 2- $\sigma$ root mean square error originating from uncertainties in the temperature profile, in the
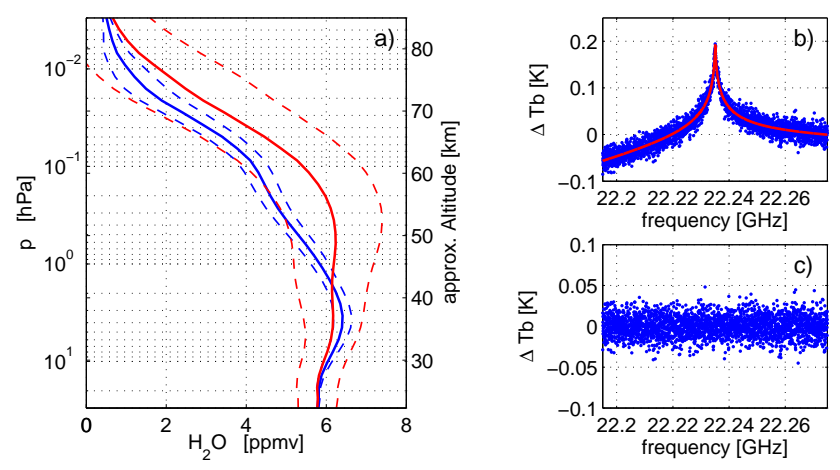

Fig. 4. (a) Example of MIAWARA-C retrieval for 21 March 2010 with a noise of $0.014 \mathrm{~K}$. The difference between the a priori profile (solid red; dashed red: a priori standard deviation) and the retrieved profile (solid blue; dashed blue: the estimated random error) is related to the strong descent observed after the stratospheric sudden warming. (b) Measured and calibrated spectrum (blue) and spectrum fitted by optimal estimation (red). (c) Residuals (difference between measured and fitted spectrum).

spectroscopic parameters and in the calibration is used. 2- $\sigma$ is taken as systematic error in order to obtain an upper limit. The random and systematic uncertainties in the temperature profile are based on Livesey et al. (2011). All errors show a characteristic decrease above $0.02 \mathrm{hPa}$ which is caused by the decrease of the diagonal elements of $\mathbf{S}_{\mathrm{a}}$ with altitude.

The systematic error of MIAWARA-C v1.1 is between 7 and $12 \%$ for all altitudes. The systematic calibration error is the largest contribution to the systematic error at lower altitudes and shows a local maximum around $1.4 \mathrm{hPa}$. The systematic spectroscopic error increases with altitude and is comparable to the calibration error at upper levels. The systematic temperature error is approximately constant with altitude. The random error at $45 \mathrm{~km}(1.1 \mathrm{hPa})$ is $6 \%$ and increases with altitude to approximately $25 \%$ at $75 \mathrm{~km}(0.012 \mathrm{hPa})$. The increase is caused by the measurement noise error, which is the dominant contribution. The random temperature error is around $1 \%$ for all altitudes. The influence of the random calibration error is strongest at lower levels with a local maximum of $4 \%$ at approximately $43 \mathrm{~km}(1.5 \mathrm{hPa})$. The shape with altitude of both systematic 
Table 2. Estimates of the errors of the relevant forward model parameters. Based on Straub et al. (2010) and Haefele et al. (2009)

\begin{tabular}{lll}
\hline Parameter & Estimated systematic error & Estimated random error \\
\hline Measurement noise & - & $0.014 \mathrm{~K}$ \\
Temperature profile & $8 \mathrm{~K}$ & $3 \mathrm{~K}$ \\
Calibration & $7 \%$ of factor for tropospheric correction & $5 \%$ of factor for tropospheric correction \\
Line intensity, $S$ & $8.7 \times 10^{-22} \mathrm{~m}^{2} \mathrm{~Hz}$ & - \\
Air broadening, $\gamma$ air & $1014 \mathrm{~Hz} \mathrm{~Pa}^{-1}$ & - \\
\hline
\end{tabular}
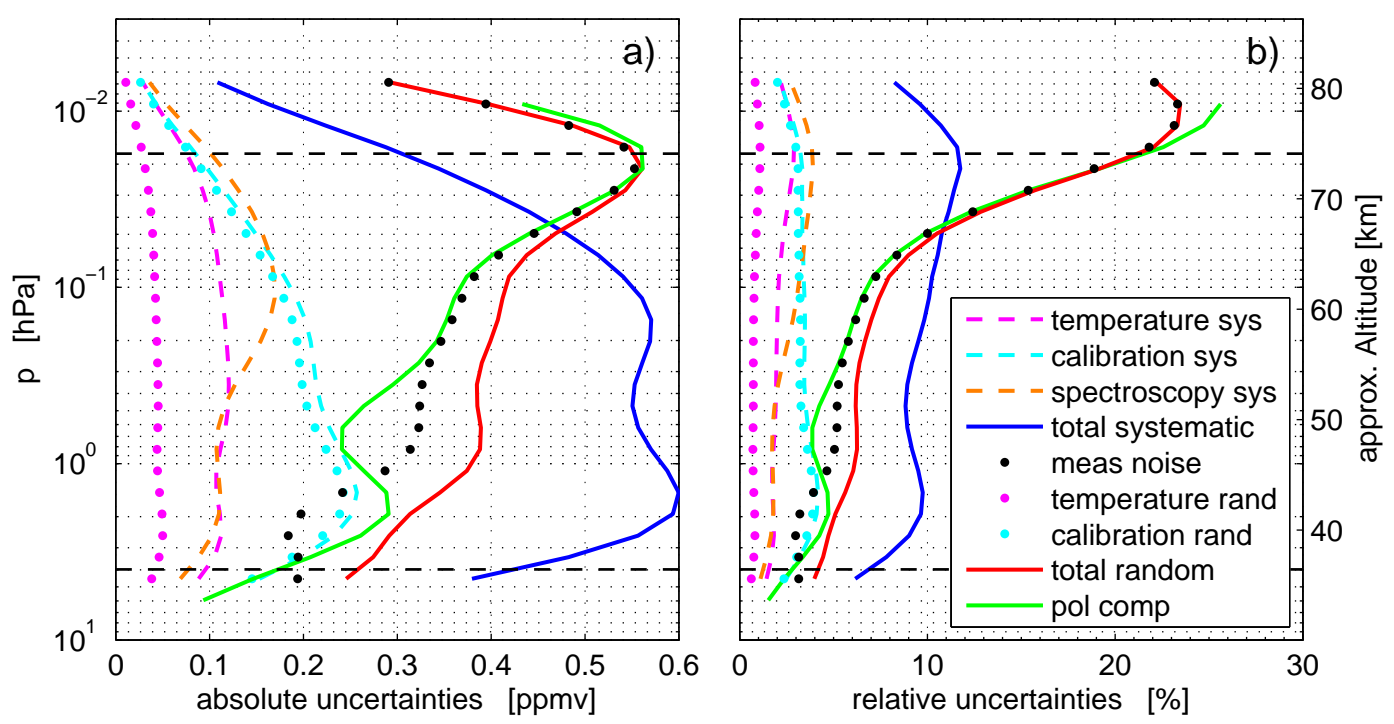

Fig. 5. Estimated uncertainties for MIAWARA-C in VMR (a) and relative to the a priori profile (b) for 21 March 2010. The 1- $\sigma$ random error (solid red) is equal to the sum of uncertainties caused by the measurement noise (dotted black), by random temperature (dotted magenta) and calibration uncertainties (dotted cyan). The systematic 2- $\sigma$ error (solid blue) is the sum of the errors caused by the uncertainties in the temperature profile (dashed magenta), in the calibration (dashed cyan) and in the spectroscopic parameters (dashed red) multiplied by 2. The measurement noise error estimated by comparing the two polarisations is shown in solid green. All plots use MIAWARA-C data with AoA $>0.5$. The dashed horizontal lines indicate the reliable altitude range $(\mathrm{AoA}>0.8)$.

and random error is constant in time, but the relative values change according to the water vapour profile of the atmosphere.

The dual-polarisation receiver of MIAWARA-C allows for the determination of the measurement noise contribution to the random error on the measured profiles directly from the measurements. For this purpose, instead of combining the spectra of the two polarisations as described in Eq. (1), we integrate the spectra of each receiver separately over the same time period, resulting in a perfect coincidence. The integrated spectra from both receiver channels are analysed separately using the same retrieval setup as v1.1. As the atmospheric conditions and sampled air mass as well as the instrumental and retrieval setup for both estimated profiles are exactly the same, the difference between them is dominated by the measurement noise. Therefore, the standard deviation of the set of difference profiles between the two polarisations divided by $\sqrt{2}$ is a direct observation of the random error caused by the measurement noise.
Profiles are retrieved separately from the two polarisations from 17 December 2010 to 9 May 2011 resulting in 1217 profile pairs. The standard deviation of the difference, which is equal to the observed variability, is shown together with the estimated errors in Fig. 5a and b. The measurement errors estimated by propagating the spectral noise are in good agreement with the measurement errors determined from the difference in the retrieved profiles for all altitudes. This indicates that the noise on MIAWARA-C's retrieved profiles agrees well with the estimation based on propagation of spectral noise.

\section{Reference instruments}

Characteristics of the reference instruments used for the validation of MIAWARA-C's v1.1 are presented in the following sections. An overview of the vertical resolution of the instruments is shown in Fig. 6. 


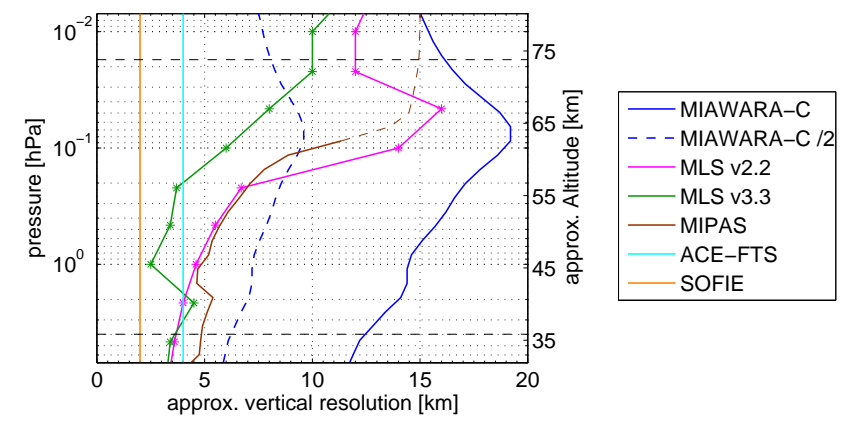

Fig. 6. Approximate vertical resolution of MIAWARA-C v1.1 and MIAWARA (blue), Aura MLS v2.2 (pink), Aura MLS v3.3 (green), MIPAS V5R_H2O_220 (brown) ACE-FTS (orange) and SOFIE (cyan). Above $0.1 \mathrm{hPa}$, MIPAS data are not used for the comparison and its vertical resolution is shown as a dotted line. The values for ACE-FTS and SOFIE are given by the instruments' field of view and are constant with altitude. For Aura MLS v2.2 and v3.3, the asterisks indicate the values specified in Livesey et al. (2007, 2011).

\subsection{MIAWARA}

MIAWARA is the first $22 \mathrm{GHz}$ radiometer for middleatmospheric water vapour built at the Institute of Applied Physics (Deuber et al., 2004). Since September 2006 has been measuring permanently from Zimmerwald (Switzerland, $46.88^{\circ} \mathrm{N}, 7.46^{\circ} \mathrm{E}, 907 \mathrm{~m}$ a.m.s.l.). After replacing the previously used acousto-optical spectrometer with a digital FFT spectrometer in 2007, the front end and the back end have remained unchanged. MIAWARA is operated within NDACC and is used for long-term monitoring of middleatmospheric water vapour and case studies of atmospheric processes.

MIAWARA and MIAWARA-C mainly differ in size and compactness and in their receiver. The part of MIAWARA which is operated outdoors is more than twice as large as MIAWARA-C. In addition, the back end of MIAWARA needs to be located indoors. The calibration schemes of MIAWARA and MIAWARA-C are identical. MIAWARA-C has two identical receiver chains whereas MIAWARA has only one, resulting in an increased integration time to cover the same altitude range. For MIAWARA the measured spectra are averaged until a noise level of $0.01 \mathrm{~K}$ is reached. This is approximately equivalent to the $0.014 \mathrm{~K}$ noise level for MIAWARA-C as MIAWARA's spectral resolution $(61 \mathrm{kHz})$ is coarser by a factor of 2 compared to MIAWARA-C.

The retrieval version of MIAWARA used in this study applies the same auxiliary data as MIAWARA-C's v1.1. The vertical resolution of both ground-based microwave radiometers is the same. Haefele et al. (2009) found a bias of $\pm 3 \%$ when comparing a similar retrieval version of MIAWARA to Aura MLS v2.2.

MIAWARA data from July 2010 to May 2011 are used as during this time both instruments have been operated from the same location. In this period, the temporal resolution of
MIAWARA was improved by changing the elevation angle of the line measurements and by installing a faster mirror drive (in mid-September 2010). These changes improved the integration time from the order of days to hours.

\subsection{Aura MLS}

Aura MLS is on board NASA's Aura satellite, which was launched in July 2004. Aura MLS covers latitudes between $82^{\circ} \mathrm{S}$ and $82^{\circ} \mathrm{N}$. Due to its Sun-synchronous polar orbit there are two overpasses at each location at fixed local times per day. Aura MLS observes thermal microwave emission in limb geometry from the ground up to $96 \mathrm{~km}$. A detailed description of Aura MLS can be found in Waters et al. (2006).

Both v2.2 and v3.3 water vapour products are used for the intercomparison. For v2.2, a thorough validation is given in Lambert et al. (2007). A bias of less than $\pm 5 \%$ was found for all altitudes when comparing to ACE-FTS. For v3.3, the quality and description document (Livesey et al., 2011) is used to characterise the data. The vertical resolution of $\mathrm{v} 2.2 / \mathrm{v} 3.3$ is $4.6 / 2.5 \mathrm{~km}$ at $1 \mathrm{hPa}$ and $12 / 10 \mathrm{~km}$ at $0.01 \mathrm{hPa}$, and the horizontal resolution is $410 / 410 \mathrm{~km}$ at $1 \mathrm{hPa}$ and $390 / 680 \mathrm{~km}$ at $0.01 \mathrm{hPa}$. Single-profile precisions are $4 / 7 \%$ at $1 \mathrm{hPa}$ and $34 / 54 \%$ at $0.01 \mathrm{hPa}$ with a systematic error of $4 / 4 \%$ and $11 / 11 \%$, respectively.

A first comparison of MIAWARA-C data obtained during the LAPBIAT campaign using Aura MLS v2.2 as a reference is presented in Straub et al. (2010). The retrieval version used for MIAWARA-C is not the same as v1.1. The main differences are the spectral bandwidth, the baseline fit and the line parameters used for the retrieval. Straub et al. (2010) found a mean difference compared to MLS v2.2 oscillating around zero of below $5 \%$ at altitudes between 6 and $0.05 \mathrm{hPa}$.

\subsection{MIPAS}

MIPAS is a mid-infrared limb emission Fourier transform spectrometer on board the Envisat satellite. It was operational from July 2002 to April 2012. It was designed to measure vertical profiles of temperature and a large variety of minor species including water vapour with global latitudinal coverage. From March 2004, it was operating with reduced spectral resolution $\left(0.0625 \mathrm{~cm}^{-} 1\right)$. A description of MIPAS is given in Fischer et al. (2008). In our study we use MIPAS water vapour data version V5R_H2O_220 obtained in nominal observation mode and processed by the Institute of Meteorology and Climate Research (IMK) at the Karlsruhe Institute of Technology in cooperation with the Instituto de Astrofisica de Andalucia (IAA). This retrieval version is based on ESA level 1 spectra from version IPF 5. The MIPAS version V5R_H2O_220 water vapour has a vertical resolution of $2.3 \mathrm{~km}$ at $20 \mathrm{~km}$ and $6.9 \mathrm{~km}$ at $50 \mathrm{~km}$, and the horizontal resolution is $206 \mathrm{~km}$ at $20 \mathrm{~km}$ and $436 \mathrm{~km}$ at $40 \mathrm{~km}$. Singleprofile precisions are $0.2 \mathrm{ppmv}$ at $10 \mathrm{~km}$ and $0.92 \mathrm{ppmv}$ at $50 \mathrm{~km}$. Version V5R_H2O_220 has not yet been validated 
but $\mathrm{V} 4 \mathrm{O} \_$H2O_203 has recently been compared using water vapour measurements obtained during the MOHAVE-2009 campaign (Leblanc et al., 2011; Stiller et al., 2012). MIPAS V4O_H2O_203 showed a wet bias of up to $10 \%$ around $45 \mathrm{~km}$ and above $55 \mathrm{~km}$ a dry bias caused by neglecting nonlocal thermodynamic equilibrium (non-LTE) effects in the retrieval (Stiller et al., 2012). V5R_H2O_220 does not yet include non-LTE effects, and therefore a similar behaviour with altitude was expected, and was indeed confirmed by internal delta validation versus version V4O_H2O_203. For that reason, MIPAS V5R_H2O_220 data are not used for altitudes above $0.1 \mathrm{hPa}$. All IMK/IAA MIPAS water vapour data after 2005 are retrieved as $\log (\mathrm{VMR})$, although provided as VMR. This has to be considered when using the averaging kernel of MIPAS for convolution since it refers to $\log (\mathrm{VMR})$ as well.

MIAWARA-C was one of the instruments participating in the MOHAVE-2009 campaign and is included in the validation of V4O_H2O_203 presented by Stiller et al. (2012). The retrieval version of MIAWARA-C used is different to v1.1. Stiller et al. (2012) found an overestimation of the estimated random errors and that MIAWARA-C is up to $10 \%$ wetter than MIPAS V4O_H2O_203.

\subsection{ACE-FTS}

ACE-FTS is operating on board the Canadian SCISAT-1 satellite, which was launched in August 2003. Routine operations started in February 2004. ACE-FTS is measuring in solar occultation mode and covers $85^{\circ} \mathrm{S}-85^{\circ} \mathrm{N}$ with the majority of the measurements occurring in the polar regions. A mission description is given in Bernath et al. (2005). The retrieval of water vapour is described in Boone et al. (2005). Water vapour profiles are retrieved between 5 and $90 \mathrm{~km}$. A first validation of ACE-FTS v2.2 is presented in Carleer et al. (2008). This shows a slight positive bias smaller than $10 \%$ in the altitude range from 15 to $70 \mathrm{~km}$ versus MIPAS (version 13, full-resolution mode), SAGE II, HALOE, POAM III and Odin-SMR. In this study, ACE-FTS v3.0 is used. Between approximately 20 and $55 \mathrm{~km}$, there are small differences of the order of $\pm 2 \%$ between ACE-FTS v2.2 and v3.0. The vertical resolution of ACE-FTS is determined by the field of view and is $3-4 \mathrm{~km}$ throughout the whole altitude range. The random uncertainty given in the data files is generally $2-5 \%$ for altitudes between 20 and $80 \mathrm{~km}$.

\subsection{SOFIE}

SOFIE is on board the Aeronomy of Ice in the Mesosphere (AIM) satellite, which was launched in April 2007. Latitudes of $\approx 65^{\circ}-85^{\circ}$ south and north are covered. Details on SOFIE are given in Gordley et al. (2009). A thorough description and validation of v1.022 water vapour is presented in Rong et al. (2010), revealing excellent agreement (0-2\%) in the Northern Hemisphere compared to ACE-FTS v2.2 and Aura MLS v2.2 in the vertical range $45-80 \mathrm{~km}$. Water vapour profiles are available for the altitude range from 15 to $95 \mathrm{~km}$. The tangent path length is approximately $280 \mathrm{~km}$ and the vertical resolution is $2 \mathrm{~km}$ throughout the whole altitude range. This study uses the v1.2 water vapour product. SOFIE has a high sensitivity resulting in low random uncertainties of less than $0.8 \%$ for altitudes below $75 \mathrm{~km}$ as given in the data files. The total systematic error is below $4 \%$ for the altitude range used.

\section{Data and method}

In the following sections, the coincidence criteria and the resulting data sets are presented and the intercomparison method is introduced.

\subsection{Coincident data sets}

For this intercomparison study, four data sets of MIAWARA-C obtained at two different sites are used: two in the polar region and two in the mid-latitudes. MIAWARA-C was measuring at the Arctic Research Centre in Sodankylä (Finland, $67.37^{\circ} \mathrm{N}, 26.63^{\circ} \mathrm{E}, 180 \mathrm{~m}$ a.m.s.l.) from January to June 2010 in the frame of the LAPBIAT 2010 campaign and again at the same location from June 2011 to February 2013. The data sets obtained at the second location span from July 2010 to May 2011 in Zimmerwald (Switzerland, $46.88^{\circ} \mathrm{N}, 7.46^{\circ} \mathrm{E}, 907 \mathrm{~m}$ a.m.s.l.). During the LAPBIAT campaign and the first part of the Zimmerwald campaign, MIAWARA-C was still equipped with its original correlation receiver, which was replaced by the dual-polarisation receiver in December 2010 for the second part of the Zimmerwald campaign and the second measurement period in Sodankylä. Table 3 summarises the dates, which receiver type was used and presents an abbreviated name for each of the four campaigns.

MIAWARA-C's profiles are compared to satellite data from Aura MLS and MIPAS for both locations. Additionally, Zimmerwald data are compared to MIAWARA, and Sodankylä data to ACE-FTS and SOFIE. ACE-FTS and SOFIE are not considered for Zimmerwald because the number of coincident profiles for ACE-FTS is too small and SOFIE does not cover mid-latitudes. ACE-FTS data are only used for the first Sodankylä campaign; for the second campaign the data were not available by the date of this publication.

Spatial coincidence is determined from the difference in latitude and longitude between MIAWARA-C's station location and a representative altitude in the satellite profile. The viewing direction of MIAWARA-C was south during both campaigns in Sodankylä, whereas the instrument was pointing north while measuring from Zimmerwald. Therefore, the criterion for collocation used for the satellite data is $+1^{\circ} /-2^{\circ}$ in latitude for Sodankylä and $+2^{\circ} /-1^{\circ}$ in latitude for Zimmerwald and $\pm 10^{\circ}$ in longitude for both locations. The winter data in Sodankylä are obtained in the vicinity of the vortex edge where steep horizontal gradients of water vapour 
Table 3. Overview of the four intercomparison periods. Upper part: receiver type of MIAWARA-C, time period and short name of the campaign as used in the figures. Lower part: number of profiles available after applying the spatial and the temporal coincidence criteria for each reference instrument.

\begin{tabular}{lrrrr}
\hline & Sodankylä10 & Zimmerwald10 & Zimmerwald11 & Sodankylä1113 \\
\hline $\begin{array}{l}\text { Receiver type } \\
\text { Time period }\end{array}$ & $\begin{array}{r}\text { correlation } \\
\text { Jan 2010-Jun 2010 }\end{array}$ & $\begin{array}{r}\text { Jul 2010-Dec 2010 } \\
\text { soda10 }\end{array}$ & $\begin{array}{r}\text { dual-polarisation } \\
\text { Diwa10 }\end{array}$ & $\begin{array}{r}\text { dual-polarisation } \\
\text { Jun 2011-Feb 2013 } \\
\text { soda1113 }\end{array}$ \\
\hline MIAWARA & - & 141 & 638 & - \\
ACE-FTS & 12 & - & - & - \\
SOFIE & 14 & - & - & 126 \\
Aura MLS v2.2 & 162 & 131 & 193 & 991 \\
Aura MLS v3.3 & 163 & 61 & 111 & 994 \\
MIPAS & 82 & & & 241 \\
\hline
\end{tabular}

are present. However, all instruments used for the validation study have a coarse horizontal resolution, in some cases up to several hundred kilometres, due to observation geometries and antenna patterns. Hence, the effect of sampling different air masses is reduced due to the horizontal smoothing. Changing the latitudinal coincidence criterion for Sodankylä, where most data were obtained in polar winter, by a degree north or south did not considerably change the outcome of the intercomparison. Therefore, no additional coincidence criterion separating the measured air masses according to the potential vorticity is applied.

After applying the spatial coincidence criterion, the profile pair (MIAWARA-C - reference measurement) that is closest in time is sought. All profiles are only used once to avoid interdependencies in the data set. In addition, a maximal temporal difference of $12 \mathrm{~h}$ for the satellites and $6 \mathrm{~h}$ for MIAWARA is applied.

An overview of the time series used for the intercomparison for the four comparison periods at the two locations is shown in Fig. 7 for 1 and $0.1 \mathrm{hPa}$. The number of profiles fulfilling the coincidence criterion for the intercomparison are summarised in Table 3.

The different vertical resolution of the instruments (Fig. 6) is taken into account for the comparison. Vertical resolutions larger than half of MIAWARA-C's resolution are regarded as comparable. In the case of comparable resolutions, the reference profiles are interpolated to MIAWARA-C's pressure grid. If the vertical resolution of a reference instrument is smaller than half the resolution of MIAWARA-C, the reference data are considered as highly resolved and convolved with the averaging kernels of the ground-based radiometer in order to make them comparable:

$\boldsymbol{x}_{\text {high,conv }}=\mathbf{A}\left(\boldsymbol{x}_{\text {high }}-\boldsymbol{x}_{\mathrm{a}}\right)+\boldsymbol{x}_{\mathrm{a}}$,

where $\boldsymbol{x}_{\text {high }}$ is the satellite profile, $\mathbf{A}$ the averaging kernel matrix and $\boldsymbol{x}_{\mathrm{a}}$ the a priori profile of the ground-based radiometer. The convolution decreases the vertical resolution and accounts for the a priori contribution of MIAWARA-C v1.1. In the reliable altitude range of MIAWARA-C v1.1 with AoA $>0.8$, the contribution of the a priori profile is small. To account for the additional smoothing introduced by the convolution, the covariance matrix of the profile with higher resolution, $\mathbf{S}_{\text {high }}$, is transformed as well. The resolution corrected covariance matrix $\mathbf{S}_{\text {high,conv }}$ belonging to $\boldsymbol{x}_{\text {high,conv }}$ is given by

$\mathbf{S}_{\text {high, conv }}=\mathbf{A S}_{\text {high }} \mathbf{A}^{T}$.

The square root of the diagonal elements of $\mathbf{S}_{\text {high,conv }}$ are the transformed error estimates belonging to $\boldsymbol{x}_{\text {high,conv }}$.

\subsection{Intercomparison strategy}

For the intercomparison we use the coincident data sets described in the previous section. The intercomparison method applied closely follows the approach presented in Stiller et al. (2012).

All comparison plots have the same structure (Figs. 8, 9, $10,11,12,13$ and 14). In panel a, the mean coincident profiles from MIAWARA-C and from the reference instrument are shown.

Panel $\mathrm{b}$ shows the bias $b_{i}$, which is the mean of the differences between MIAWARA-C and reference instrument at altitude level $i$. The standard error of the bias is given by

$\sigma_{i, \text { bias }}=\sqrt{\frac{\sum_{n=1}^{N_{i}}\left(x_{i, \text { mia }-c}(n)-x_{i, \text { ref }}(n)-b_{i}\right)^{2}}{N_{i}\left(N_{i}-1\right)}}$,

where $N_{i}$ is the number of data pairs at level $i$, and is shown as horizontal error bars in panel b. For large coincident data sets $\sigma_{i \text {,bias }}$ is hardly visible. The bias is considered as clearly insignificant if the interval $b_{i} \pm \sigma_{i \text {, bias }}$ includes zero. In addition, the bias is compared to the estimated systematic error. The systematic error of the reference instrument is not considered reducing the combined estimated systematic error to the systematic error of MIAWARA-C. A bias outside the range of the estimated systematic error hints towards either an uncorrected bias of the reference instrument or an underestimation of MIAWARA-C's systematic error. 

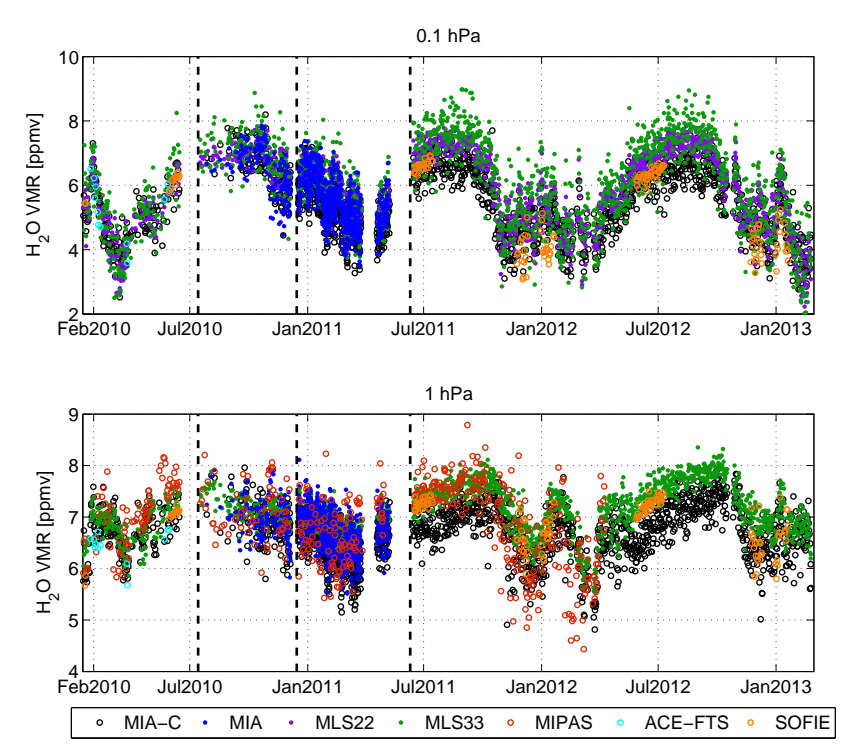

Fig. 7. Overview of the data used for the intercomparison on two pressure levels. The black dashed vertical lines indicate the beginning of a new comparison period. Some of the satellite data are convolved with MIAWARA-C's averaging kernels, and only data points fulfilling the coincidence criterion are shown (see Sect. 4.1). In April 2011 there is a gap in Aura MLS's measurements which is also present in MIAWARA-C and MIAWARA data because of missing temperature profiles.

Panel c presents a validation of the random error. The error provided along with the satellite profiles is assumed to be purely random and together with the estimated random error of MIAWARA-C builds the combined estimated random error. The standard deviation of the mean difference $\sigma_{i \text {, diff, }}$ herein called observed variability, is expected to be equal to the combined estimated random error of the instruments neglecting non-perfect coincidence. Non-perfect coincidence results in increased observed variability due to variations in atmospheric water vapour in both space and time. Therefore, observed variability larger than the combined random error can either be explained by non-perfect coincidence or underestimation of the random error of MIAWARA-C, of the reference instrument or of both.

To investigate the ability of the instrument to monitor temporal variations, correlation coefficients in time are determined for each altitude level and are shown in panel $\mathrm{d}$ of the comparison plots. The correlation coefficient of the coincident profiles is reduced by non-perfect coincidence and by the random errors and varying systematic errors of the instruments. All correlation coefficients displayed have a confidence level above $95 \%$.

\section{Results of the intercomparison}

The results of the intercomparison following the description given in Sect. 4.2 are presented for each reference instrument. Short names for the four comparison periods are defined in Table 3 to increase the readability of the figures. Additionally, "conv" is used as an abbreviation for convolved.

\subsection{MIAWARA}

For the Zimmerwald campaign with MIAWARA-C measuring next to MIAWARA, a total of 779 coincident profile pairs are found -141 with the old and 638 with the new receiver of MIAWARA-C. Both instruments are facing in a similar direction: MIAWARA is pointing north and MIAWARA-C is pointing to an azimuth of $18^{\circ}$ east of north. The two instruments use the same measurement principle, the same calibration scheme, a similar retrieval setup and have the same vertical resolution. Therefore, the profiles are compared directly without applying the averaging kernels, and the uncertainties estimated for MIAWARA-C are assumed to be valid for MIAWARA as well. As the two ground-based microwave instruments use the same auxiliary data for the retrieval, contributions from uncertainties in the temperature profile and in the spectroscopic parameters are not considered for the estimated error, reducing the systematic error to the systematic calibration error. The estimated random error is the combination of measurement noise and random calibration error for both instruments. For consistency with the other reference instruments, the systematic error is given by the systematic calibration error of MIAWARA-C only.

The results of the comparison are shown in Fig. 8. The bias for the correlation receiver data set, shown in Fig. 8b, oscillates around zero, reaching the largest deviation of $-0.11 \mathrm{ppmv}$ at $45 \mathrm{~km}(1.1 \mathrm{hPa})$. For the dualpolarisation receiver there is a dry bias of MIAWARA-C above $45 \mathrm{~km}(1.1 \mathrm{hPa})$ and throughout the mesosphere ranging from -0.12 to $-0.3 \mathrm{ppmv}$. The bias is generally within the estimated systematic uncertainty of MIAWARA-C except for the uppermost altitudes.

The standard deviation of the differences together with the combined estimated random error, presented in Fig. 8c, indicates that both shape and magnitude are similar for the two different receivers of MIAWARA-C. Above $45 \mathrm{~km}(1 \mathrm{hPa})$ the estimated and the observed random variations agree in shape and in magnitude. At the lowermost altitudes, below $45 \mathrm{~km}(1.1 \mathrm{hPa})$, the standard deviation of the differences is larger than the combined estimated random error.

The correlation coefficients of the coincident time series for all altitudes for the two periods of the Zimmerwald campaign are shown in Fig. 8d. For the first period of the Zimmerwald campaign the correlation coefficient is not significant below $42 \mathrm{~km}(1.7 \mathrm{hPa})$. Above $55 \mathrm{~km}$ the values are larger than 0.5 and reach a maximum of 0.7 around $65 \mathrm{~km}$ $(0.09 \mathrm{hPa})$. For the dual-polarisation receiver the correlation coefficient is significant for all altitudes and generally larger than 0.5 above $42 \mathrm{~km}(1.7 \mathrm{hPa})$. Below $42 \mathrm{~km}$ the correlation coefficient decreases. 


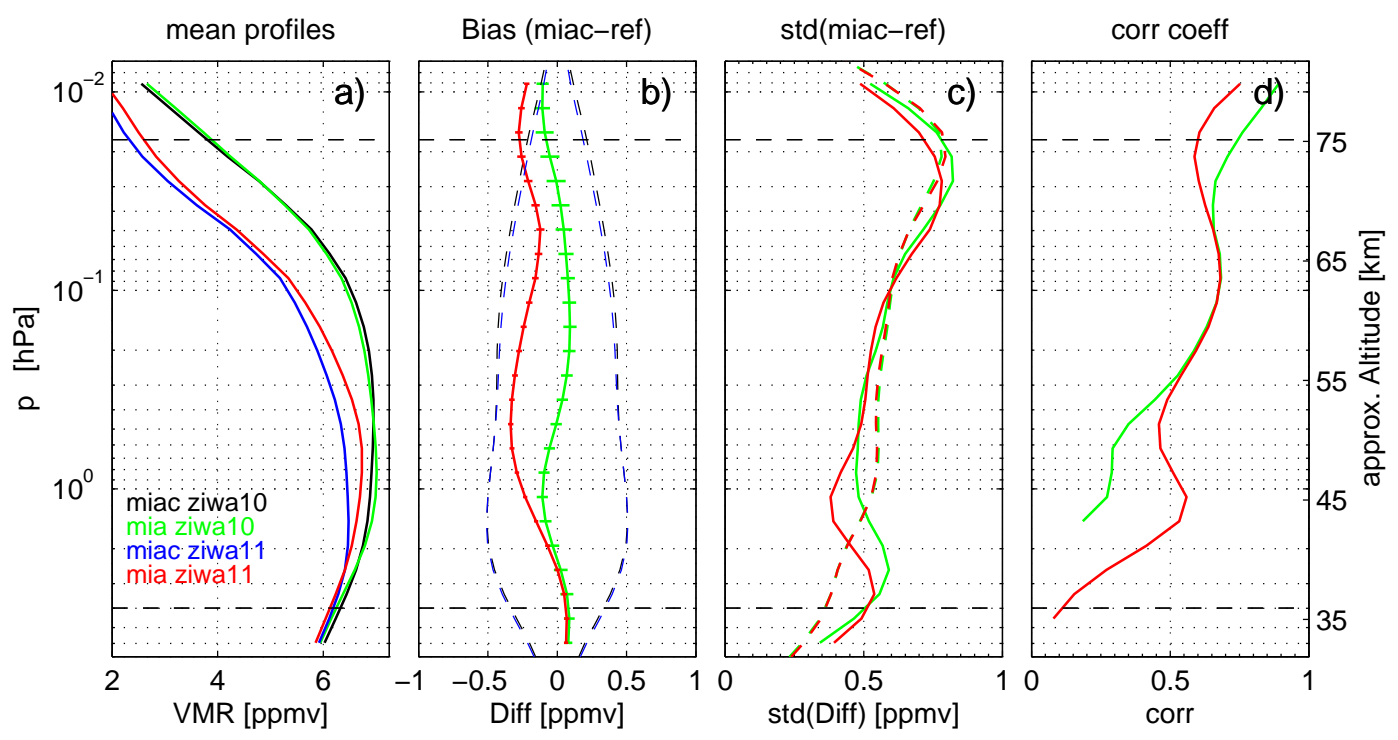

Fig. 8. Intercomparison MIAWARA-C - MIAWARA for Zimmerwald10 and for Zimmerwald11. (a) Mean coincident profiles for Zimmerwald10 (MIAWARA: green, MIAWARA-C: black) and for Zimmerwald11 (MIAWARA: red, MIAWARA-C: blue). (b) Bias (solid) with standard error (horizontal) with respect to MIAWARA (Zimmerwald10: green, Zimmerwald11: red) together with the estimated systematic error of MIAWARA-C (black dashed). (c) Standard deviation of differences (solid) and combined random error of the instruments (dashed). (d) Correlation coefficients. All plots use MIAWARA/MIAWARA-C data with AoA $>0.5$. The dashed horizontal lines indicate the reliable altitude range $(\mathrm{AoA}>0.8)$.

\subsection{Aura MLS}

For Aura MLS both v2.2 and v3.3 are used. Because of the different vertical resolutions of the two versions, different comparison strategies are used: the vertical resolution of v3.3 is better by more than a factor of 2 compared with MIAWARA-C for all altitudes except for the uppermost level $(0.022 \mathrm{hPa})$, justifying a convolution with the averaging kernels, whereas v2.2 data are convolved below $0.1 \mathrm{hPa}$ and compared directly above $0.1 \mathrm{hPa}$.

The good spatial and temporal coverage of Aura MLS in combination with the coincidence criterion used leads to large data sets for v2.2 (v3.3), respectively, consisting of 162 (163) profiles for Sodankylä10, 131 (132) for Zimmerwald with the correlation receiver, 193 (191) for Zimmerwald with the dual-polarisation receiver and 991 (994) for Sodankylä11-13.

The comparison of v3.3/v2.2 using data obtained with the correlation receiver of MIAWARA-C are displayed in Fig. 9. The biases for Sodankylä10 shown in Fig. 9b have a similar shape to Zimmerwald10 in Fig. 9f throughout the whole reliable altitude range. The bias is within the estimated systematic uncertainties of MIAWARA-C for both versions and for both campaigns. Compared to v3.3, MIAWARA-C shows a dry bias above $45 \mathrm{~km}(1.1 \mathrm{hPa})$, which is slightly increasing with altitude of maximum -0.17 ppmv for Sodankylä10 and of maximum -0.43 ppmv for Zimmerwald10. Below $45 \mathrm{~km}$ the bias compared to v3.3 is small. Compared to v2.2, there is a wet bias of MIAWARA-C that is smaller than $0.22 \mathrm{ppmv}$ up to approximately $60 \mathrm{~km}(0.15 \mathrm{hPa})$ and a slight dry bias above for Sodankylä10. For Zimmerwald with the correlation receiver the bias below $45 \mathrm{~km}(1.1 \mathrm{hPa})$ is small, above there is a dry bias comparable to the one observed for v3.3. The intercomparisons of the observed and estimated random errors, presented in Fig. 9c and g, are generally in good agreement for both campaigns. Above approximately $60 \mathrm{~km}(0.15 \mathrm{hPa})$ for v2.2 the observed random variations are slightly higher than the estimated combined random error, whereas v3.3 hints towards an underestimation of the combined random error. The correlation coefficients for both MLS versions are shown in Fig. 9d and h for Sodankylä10 and Zimmerwald10, respectively. For Sodankylä10 the correlation for both MLS versions is larger than 0.66 for all levels above $45 \mathrm{~km}(1.1 \mathrm{hPa})$ and decreases below. The correlation coefficients for Zimmerwald10 range from 0.33 to 0.83 and are lower than for Sodankylä10. MLS v2.2 has slightly higher values than v3.3.

The comparisons with MLS v2.2 and v3.3 using MIAWARA-C data obtained with the dual-polarisation receiver for Zimmerwald11 and Sodankylä11-13 are shown in Fig. 10. Compared to MLS v3.3 and v2.2, the biases of MIAWARA-C show a similar altitude dependence for both comparison periods. Compared to v3.3, MIAWARA-C has almost no bias at the lowermost altitudes. Above $45 \mathrm{~km}(1.1 \mathrm{hPa})$ there is an increasing dry bias of less than -0.64 ppmv for Zimmerwald 11 and less than -0.63 ppmv for Sodankylä11-13. MLS v2.2 shows similar results at upper levels but seems to be drier than v3.3, resulting in a 

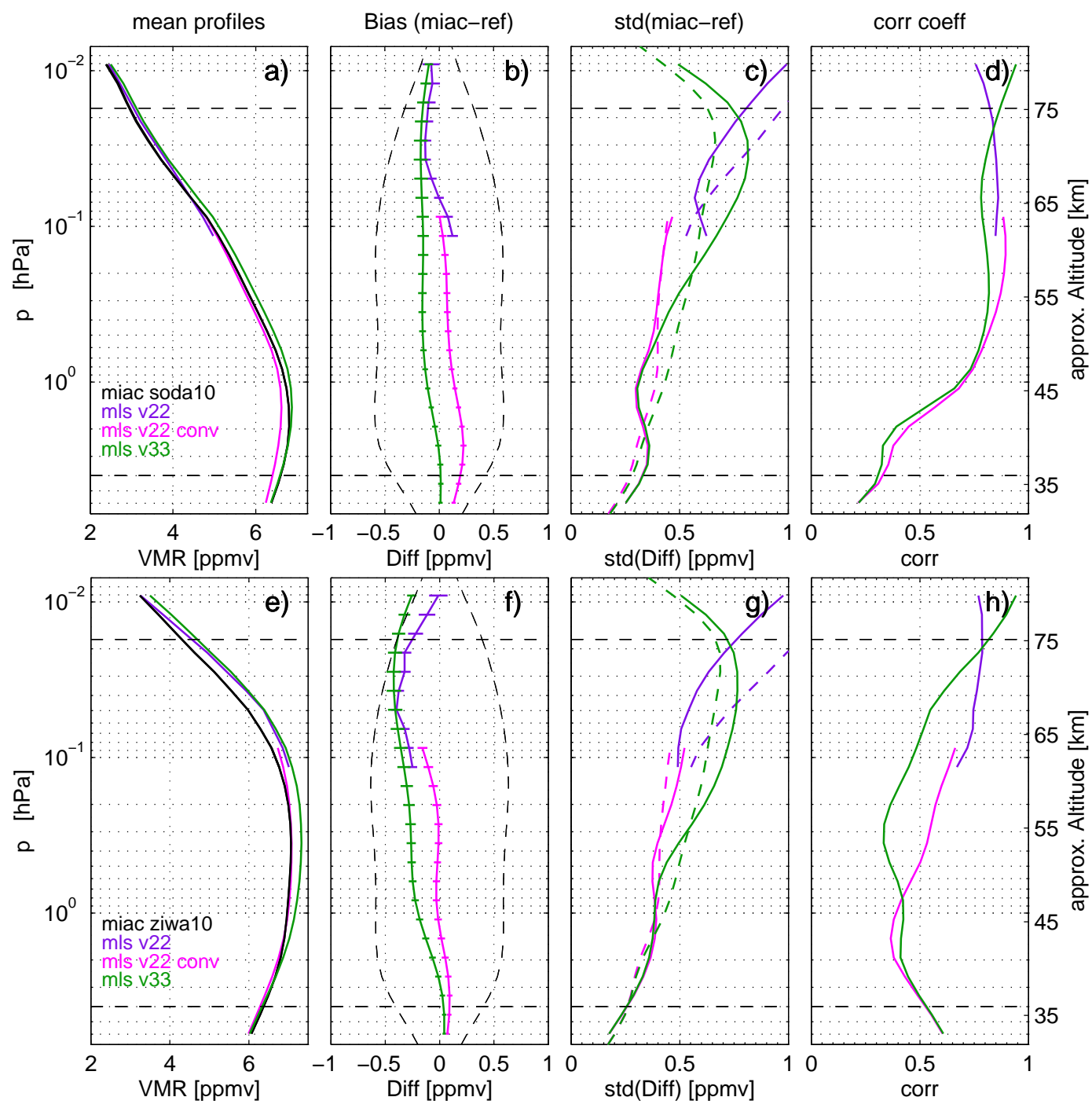

Fig. 9. Intercomparison MIAWARA-C (with correlation receiver) - MLS for Sodankylä10 campaign (a-d) and for Zimmerwald10 (e-h). (a, e) Mean coincident profiles of MLS v2.2 (pink: convolved, purple: interpolated), MLS v3.3 (green) and MIAWARA-C (black). (b, f) Bias (solid) with standard error (horizontal) with respect to MLS v2.2 (pink: convolved, purple: interpolated) and MLS v3.3 (green) together with the estimated systematic error of MIAWARA-C (black dashed). (c, g) Standard deviation of differences (solid; pink for MLS v2.2 convolved, purple for MLS v2.2 interpolated, green for MLS v3.3) and combined random error of the instruments (dashed). (d, h) correlation coefficients. All plots use MIAWARA-C data with AoA $>0.5$. The dashed horizontal lines indicate the reliable altitude range $($ AoA $>0.8)$.

wet bias of MIAWARA-C below $42 \mathrm{~km}(1.7 \mathrm{hPa})$ of less than 0.09 ppmv and 0.17 ppmv for Zimmerwald 11 and Sodankylä11-13, respectively. Above approximately $50 \mathrm{~km}$ the estimated systematic errors of MIAWARA-C are similar to the magnitudes of the biases. The observed variations presented in panels $\mathrm{c}$ and $\mathrm{g}$ of Fig. 10 have local maxima around $40 \mathrm{~km}$ of approximately $0.4 \mathrm{ppmv}$ for both versions and campaigns, which are larger than the combined estimated random errors. At upper altitudes, the observed variations are similar to the estimated random errors for v2.2, whereas v3.3 shows higher observed variability by up to a factor of 1.4. The correlation coefficients for both versions are shown in Fig. 10d for Sodankylä10 and Fig. 10h for Zimmerwald11-13. The correlation coefficient profiles have a different shape for the two campaigns: Sodankylä11-13 correlations are larger than 0.64 for all altitudes and larger than 0.75 above $45 \mathrm{~km}$ $(1.1 \mathrm{hPa})$. The values for Zimmerwald11 show a decrease below $45 \mathrm{~km}(1.1 \mathrm{hPa})$ and are generally lower. The correlation coefficient for MLS v3.3 is lower than for MLS v2.2.

\subsection{MIPAS}

The coincidence criterion produced a data set consisting of 82 coincident profiles for Sodankylä10, 61 for Zimmerwald10, 111 for Zimmerwald11 and 241 for Sodankylä1113. For the comparison MIPAS V5R_H2O_220 is only used 

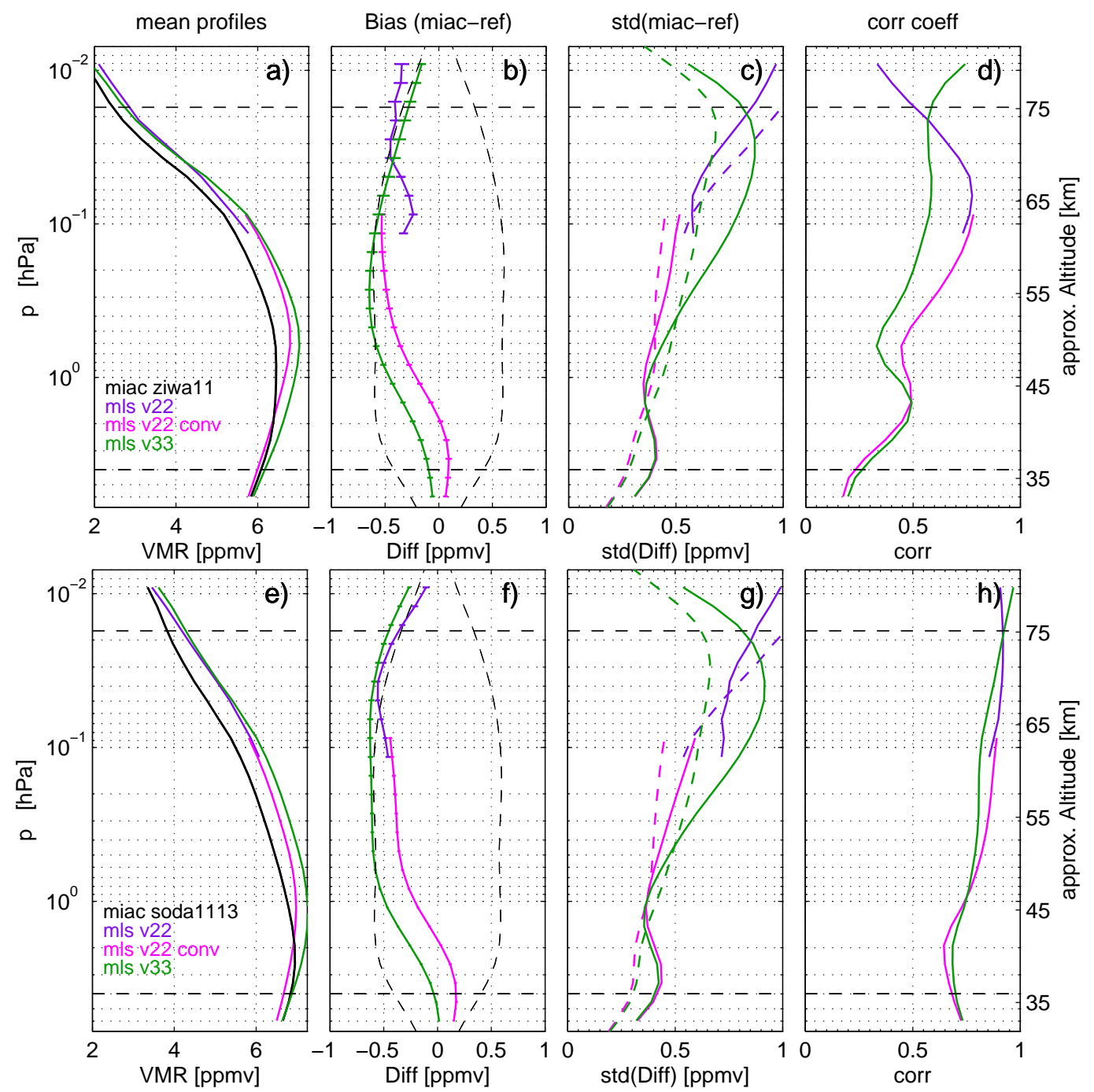

Fig. 10. Intercomparison MIAWARA-C (with dual-polarisation receiver) - MLS for Zimmerwald11 (a-d) and for Sodankylä11-13 (e-h). (a, e) Mean coincident profiles of MLS v2.2 (pink: convolved, purple: interpolated), MLS v3.3 (green) and MIAWARA-C (black). (b, f) Bias (solid) with standard error (horizontal) with respect to MLS v2.2 (pink: convolved, purple: interpolated) and MLS v3.3 (green) together with the estimated systematic error of MIAWARA-C (black dashed). (c, g) Standard deviation of differences (solid; pink for MLS v2.2 convolved, purple for MLS v2.2 interpolated, green for MLS v3.3) and combined random error of the instruments (dashed). (d, h) Correlation coefficients. All plots use MIAWARA-C data with AoA $>0.5$. The dashed horizontal lines indicate the reliable altitude range $(\mathrm{AoA}>0.8)$.

below $0.1 \mathrm{hPa}$ and convolved with MIAWARA-C's averaging kernels.

The results obtained with the correlation receiver of MIAWARA-C are shown in Fig. 11. The means of the differences are presented in Fig. 11b. For Sodankylä10, MIPAS observes the water vapour maximum at a higher altitude than MIAWARA-C. This results in a dry bias of MIAWARA-C of less than $0.42 \mathrm{ppmv}$ above $2 \mathrm{hPa}(40 \mathrm{~km})$. For Zimmerwald10, a small dry bias of MIAWARA-C is observed below $0.5 \mathrm{hPa}(48 \mathrm{~km})$, and above there is a wet bias with a maximum of 0.98 ppmv. The dry biases at lower altitudes are within the estimated systematic error of MIAWARA$\mathrm{C}$ alone for both periods, whereas the wet bias observed during the Zimmerwald11-13 campaign exceeds the estimated systematic error for altitudes above $0.3 \mathrm{hPa}(55 \mathrm{~km})$. The observed random variations shown in Fig. $11 \mathrm{c}$ are higher than the estimated errors for most altitudes and both campaigns. The observed random variation exceeds the combined estimated errors by up to a factor of 2.5 for Zimmerwald 10 and by up to a factor of 1.6 for Sodankylä10. The correlation coefficient, shown in Fig. 11d, is only significant below $45 \mathrm{~km}(1.1 \mathrm{hPa})$ for Zimmerwald10. For Sodankylä10 the correlation between MIAWARA-C and MIPAS is not significant at the lowermost altitude levels, whereas at the higher altitudes the correlation is significant and has values 0.43 and 0.70 . 

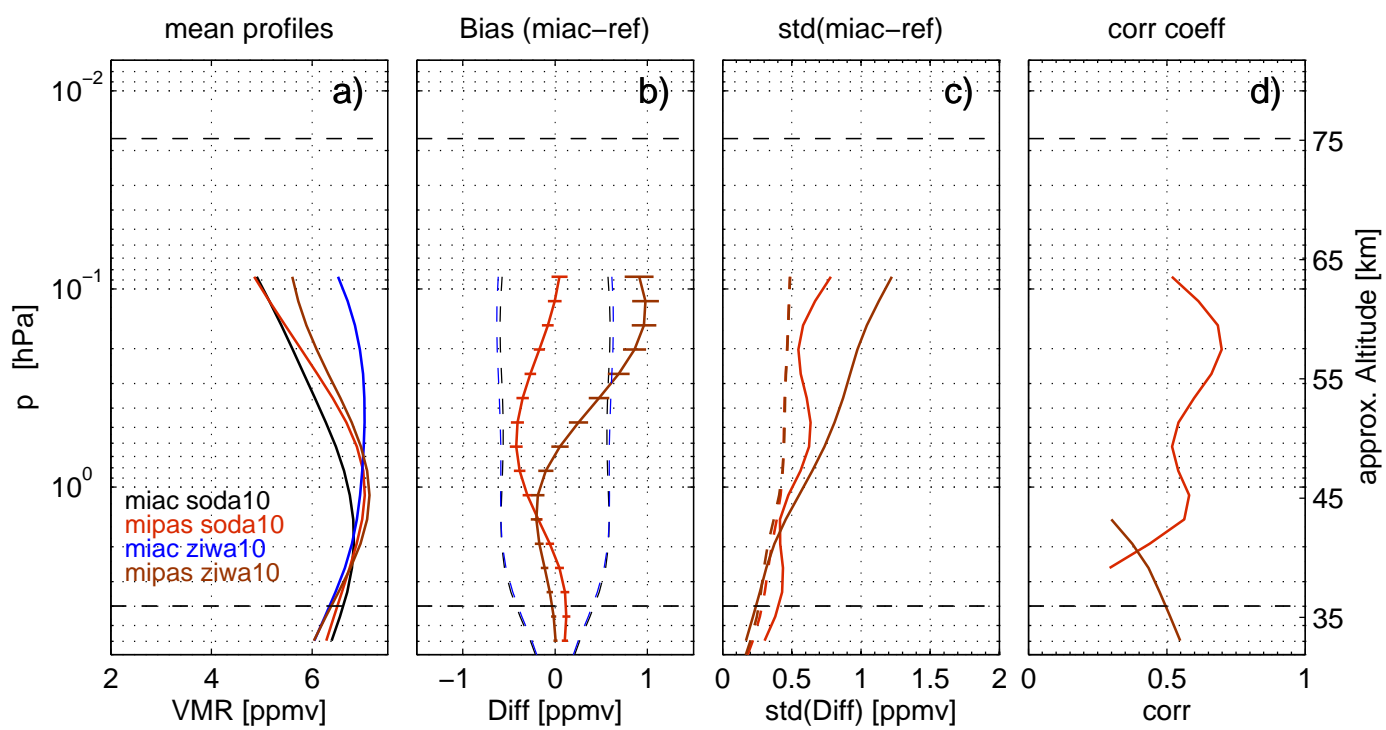

Fig. 11. Intercomparison MIAWARA-C - MIPAS for Sodankylä10 (red) and Zimmerwald10 campaign (brown). (a) Mean coincident profiles for Sodankylä10 (MIPAS: red, MIAWARA-C: black) and for Zimmerwald10 (MIPAS: brown, MIAWARA-C: blue). (b) Bias (solid Sodankylä10: red, Zimmerwald10: brown) with standard error (horizontal) together with the estimated systematic error of MIAWARA-C (Sodankylä10: black, Zimmerwald10: blue). (c) Standard deviation of differences (solid) and combined random error of the instruments (dashed): red for Sodankylä10 and brown for Zimmerwald10 campaign. (d) Correlation coefficients. All plots use MIAWARA-C data with AoA $>0.5$. The dashed horizontal lines indicate the reliable altitude range $($ AoA $>0.8)$.

Figure 12 shows the results obtained with the dualpolarisation receiver. The biases presented in Fig. 12b show a similar shape for the two comparison periods: a dry bias of MIAWARA-C of less than $0.4 \mathrm{ppmv}(0.27 \mathrm{ppmv})$ around $40-45 \mathrm{~km}$ and a wet bias smaller than $0.61 \mathrm{ppmv}(0.46 \mathrm{ppmv})$ around 50-60 km for Zimmerwald11 (Sodankylä11-13). For Sodankylä11-13 the maximum of MIPAS water vapour is slightly higher compared to MIAWARA-C (similar to Sodankylä10). In addition, the mean profile of MIPAS shows a more pronounced maximum, which is not observed by MIAWARA-C. The biases are within the estimated systematic error of MIAWARA-C alone for both periods. The observed random variations presented in Fig. 11c are larger than the estimated errors for all altitudes and both campaigns. The observed random variation exceeds the combined estimated errors by up to a factor of 2.4 for Sodankylä11-13 and by up to a factor of 3.3 for Zimmerwald11. The correlation, shown for both periods in Fig. 11d, is for Zimmerwald11 only significant around $60 \mathrm{~km}$. For Sodankylä11-13 the correlation is larger than 0.5 above $45 \mathrm{~km}$ and shows a decrease below.

\subsection{ACE-FTS}

The coincidence criterion results in a data set of 12 coincident ACE-FTS profiles for Sodankylä10. Because the vertical resolution of ACE-FTS is $3-4 \mathrm{~km}$ at all altitudes, which is clearly higher than the vertical resolution of MIAWARA-C, MIAWARA-C's averaging kernels are applied in the whole altitude range.
The profile comparisons of ACE-FTS are presented in Fig. 13 for Sodankylä10. Due to the small number of coincident profiles, the standard error of the bias is larger than that for the results previously presented. Nevertheless, the bias together with its standard error is within the systematic error for all altitudes. Figure $13 \mathrm{~b}$ indicates a wet bias of less than 0.33 ppmv through the whole altitude range of MIAWARA-C compared to ACE-FTS. The observed variations are slightly higher than the random error above $55 \mathrm{~km}$ $(0.3 \mathrm{hPa})$, as shown in Fig. $13 \mathrm{c}$, by up to a factor of 1.2. At lower altitudes the observed and combined estimated random uncertainties are similar. The observed random variations show a local maximum below $40 \mathrm{~km}$ similar to the ones observed by comparing to MIAWARA, Aura MLS and MIPAS.

The correlation coefficients are shown in Fig. 13d. At the lowermost levels the correlation is not significant. Above $43 \mathrm{~km}(1.5 \mathrm{hPa})$, the correlation coefficient is between 0.62 and 0.92 .

\subsection{SOFIE}

SOFIE has a much higher vertical resolution than MIAWARA-C ( $2 \mathrm{~km}$ at all altitudes). Therefore, SOFIE profiles are convolved with MIAWARA-C's averaging kernels for all altitudes. Applying the coincidence criterion results in a data set of 14 coincident profiles for Sodankylä10 and 126 for Sodankylä11-13.

The mean coincident profiles are displayed in Fig. 14a. The bias shown in Fig. 14b oscillates with altitude for both 

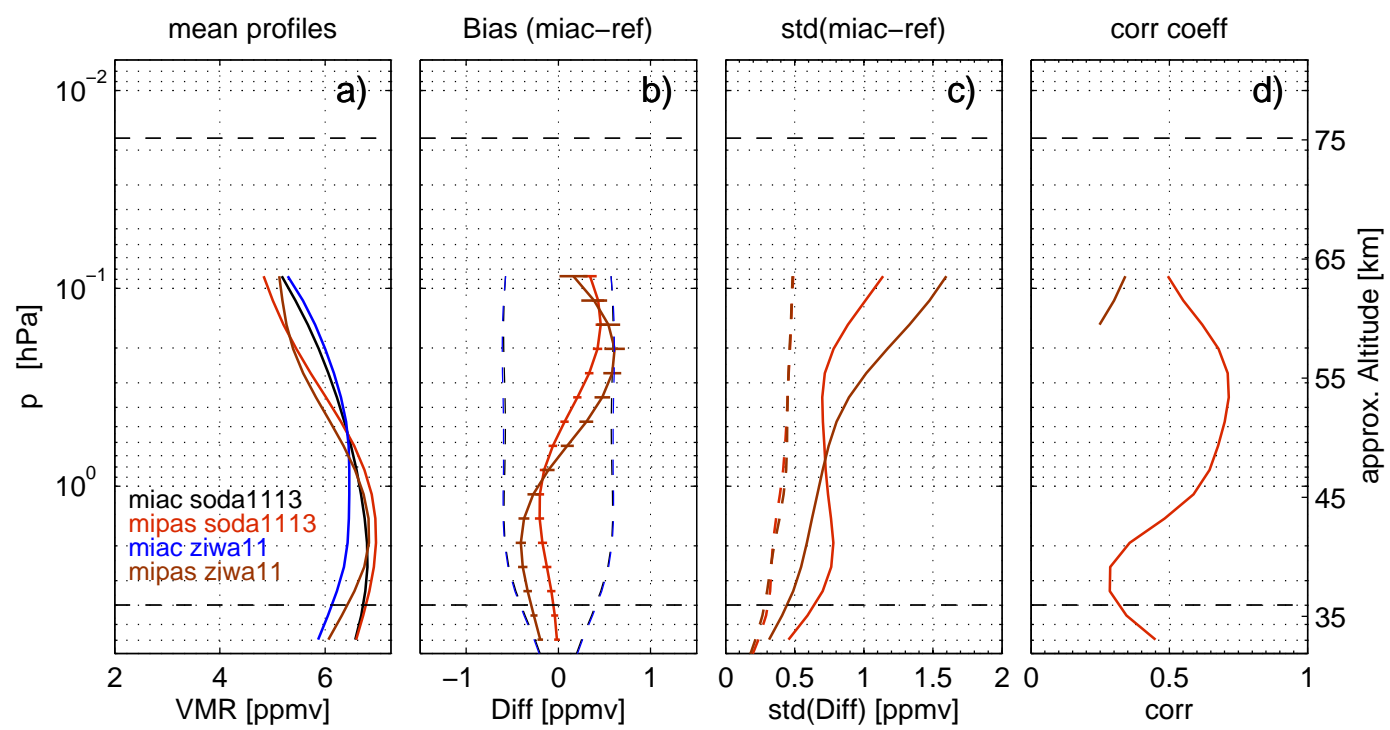

Fig. 12. Intercomparison MIAWARA-C - MIPAS for Sodankylä11-13 (red) and Zimmerwald11 campaign (brown). (a) Mean coincident profiles for Sodankylä11-13 (MIPAS: red, MIAWARA-C: black) and for Zimmerwald11 (MIPAS: brown, MIAWARA-C: blue). (b) Bias (solid, Sodankylä11-13: red, Zimmerwald11: brown) with standard error (horizontal) together with the estimated systematic error of MIAWARA-C (Sodankylä11-13: black, Zimmerwald11: blue). (c) Standard deviation of differences (solid) and combined random error of the instruments (dashed), red for Sodankylä11-13 and brown for Zimmerwald11 campaign. (d) Correlation coefficients. All plots use MIAWARA-C data with $\mathrm{AoA}>0.5$. The dashed horizontal lines indicate the reliable altitude range $(\mathrm{AoA}>0.8)$.

Sodankylä campaigns. These oscillations are mainly caused by a difference in the altitude of the water vapour maximum, MIAWARA-C observes the maximum approximately $5 \mathrm{~km}$ lower than SOFIE. In addition, the profiles of the two instruments show a different shape leading to additional local extrema of the bias. The extreme values for Sodankylä10 are $0.68 \mathrm{ppmv}$ at $40 \mathrm{~km}(2.6 \mathrm{hPa}),-0.49 \mathrm{ppmv}$ at $53 \mathrm{~km}(0.36 \mathrm{hPa})$ and $0.32 \mathrm{ppmv}$ at $74 \mathrm{~km}(0.02 \mathrm{hPa})$. For Sodankylä11-13 there is a slight wet bias at the lowermost levels, a dry bias of $-3.1 \mathrm{ppmv}$ at $45 \mathrm{~km}(1.1 \mathrm{hPa})$ and a wet bias around $65 \mathrm{~km}(0.09 \mathrm{hPa})$ with a maximum of $0.54 \mathrm{ppmv}$. The stratospheric wet bias for Sodankylä10 is outside of the range of MIAWARA-C's systematic error and the mesospheric wet biases are on the limit. As for ACE-FTS, the small number of coincident observations leads to a larger standard error of the bias. In contrast to most other comparison data sets, the observed variations determined using MIAWARA-C and SOFIE for Sodankylä10 are in agreement with the estimated random errors throughout the reliable altitude range (AoA > 0.8), as shown in Fig. 14c. For Sodankylä11-13, the observed variations exceed the combined estimated random error by up to a factor of 1.6.

The correlation coefficients for SOFIE, presented in Fig. $14 \mathrm{~d}$, reach values between 0.51 and 0.94 for altitudes

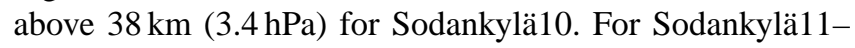
13, the correlation is below 0.5 for altitudes below $45 \mathrm{~km}$. From there on, there is a steady increase with a maximum of 0.97 at the uppermost level.

\section{Summary and discussion}

To facilitate the comparison with other studies, Fig. 15 shows a compilation of the biases found for all campaigns in percent (mean of the differences relative to MIAWARA-C). The biases for all campaigns are generally within $\pm 13 \%$.

Compared to MIAWARA, the data obtained with the correlation receiver of MIAWARA-C show a bias oscillating around zero with values between -2.3 and $1.3 \%$. For the second period of the Zimmerwald campaign with the dualpolarisation receiver, a dry bias relative to MIAWARA is observed increasing with altitude of less than $-11 \%$. With respect to Aura MLS v3.3, there is almost no bias at the lowest altitude level but an increasing dry bias for higher altitudes for all campaigns. The maximum of this dry bias is $-5 \%$ for Sodankylä10, -9 and $-12 \%$ for Zimmerwald with the correlation and the dual-polarisation receiver, respectively, and $-13 \%$ for Sodankylä11-13. Comparing to Aura MLS v2.2 the observed bias has a similar shape but it is shifted by approximately $1.2-3.5 \%$ to the wetter side, resulting in a wet bias of MIAWARA-C at lowest altitudes smaller than $4 \%$ and a slightly lower dry bias in the mesosphere. For Sodankylä10, the bias relative to Aura MLS v2.2 ranges from -3.7 to $3.4 \%$ which is of the same order of magnitude as the results presented in Straub et al. (2010) for the same time period with a different retrieval version of MIAWARA-C.

The coincident data sets of ACE-FTS and SOFIE for Sodankylä10 are small, containing only 12 and 14 profile pairs, respectively. This could limit the statistical relevance of the 

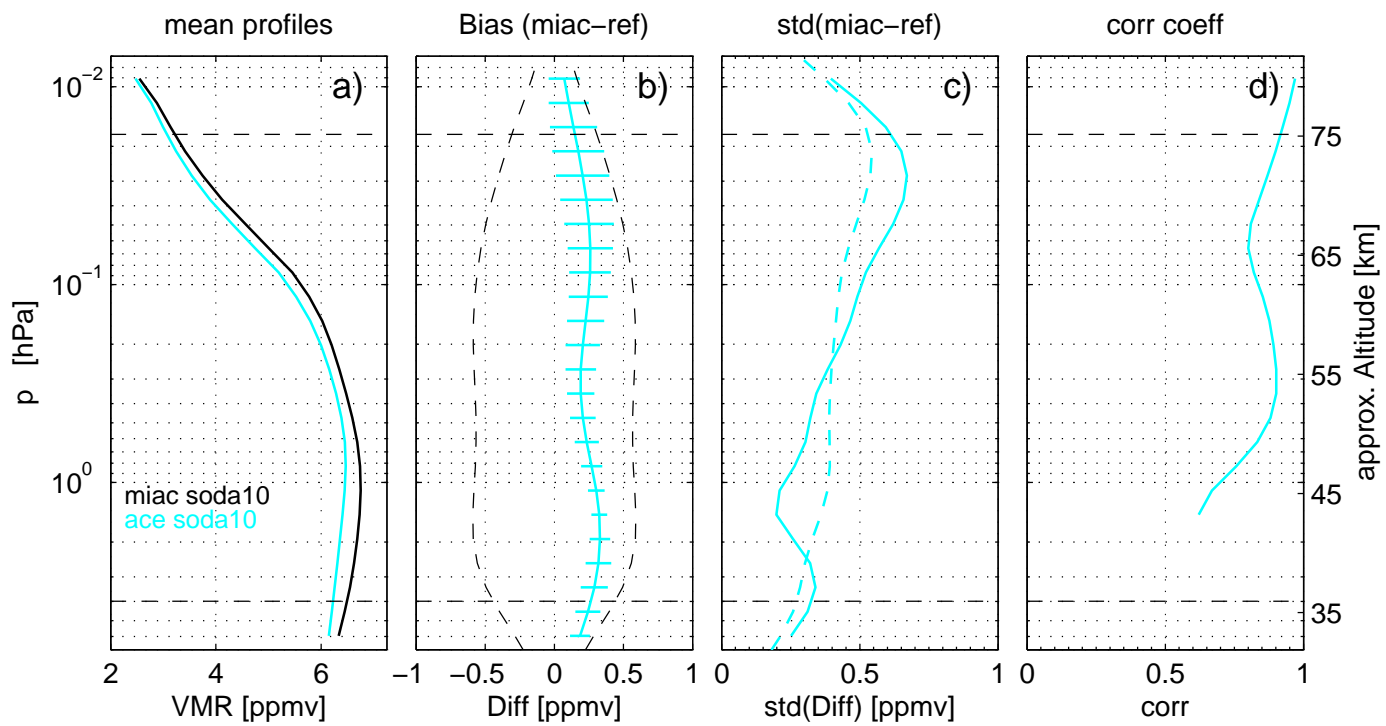

Fig. 13. Intercomparison MIAWARA-C - ACE-FTS for Sodankylä10. (a) Mean coincident profiles of ACE-FTS (cyan)/MIAWARA-C (black) for 2010. (b) Bias (solid, cyan) and its standard error (horizontal) together with the estimated systematic error of MIAWARA-C (black dashed). (c) Standard deviation of differences (solid, cyan) and combined random error of the instruments (dashed). (d) Correlation coefficient. All plots use MIAWARA-C data with AoA $>0.5$. The dashed horizontal lines indicate the reliable altitude range $($ AoA $>0.8)$.

comparison. ACE-FTS hints towards an almost constant wet bias of MIAWARA-C around $5 \%$. Contrasting the results presented here, Carleer et al. (2008) report ACE-FTS to be too wet by 3 to $10 \%$ in the altitude range 15 to $70 \mathrm{~km}$. The bias between SOFIE and MIAWARA-C shows a strong oscillation for both Sodankylä10 and Sodankylä11-13, with maxima below $\pm 10 \%$. For Sodankylä10 there is a wet bias of $10 \%$ at the lowermost levels, a dry bias of $7.5 \%$ around $55 \mathrm{~km}$ and a wet bias of $5 \%$ at the upper limit. For Sodankylä11-13 the local maxima are increasing with altitude starting with a wet bias below $1.5 \%$, a dry bias of $5 \%$ around $45 \mathrm{~km}$ and a wet bias of $10 \%$ around $65 \mathrm{~km}$.

The mean of the differences relative to MIPAS shows a dry bias of MIAWARA-C of $-6.5 \%$ around $5 \mathrm{hPa}(50 \mathrm{~km})$ for Sodankylä10. For the other three campaigns, the shape of the bias with respect to MIPAS is characterised by a dry bias around $40-45 \mathrm{~km}$ of $-3 \%$ for Zimmerwald 10 and for Sodankylä11-13, and of $-6 \%$ for Zimmerwald11, while around $55 \mathrm{~km}$ there is a wet bias of $15 \%$ for the correlation receiver (Zimmerwald10) and of $10 \%$ for Zimmerwald11 and $8 \%$ for Sodankylä11-13. According to Stiller et al. (2012), MIPAS V4O_H2O_203 has a tendency to be biased high by up to $10 \%$ around $45 \mathrm{~km}$. Hence, the observed bias between MIPAS and MIAWARA-C v1.1 around $45 \mathrm{~km}$ might originate from MIPAS. In addition, Stiller et al. (2012) found that MIAWARA-C is up to $10 \%$ wetter than MIPAS, however using different retrieval versions. This is consistent with the wet bias observed in this study compared to MIPAS. For Sodankylä, especially for Sodankylä11-13, the shape of the bias relative to MIPAS shows similarities to the one relative to SOFIE. Both MIPAS and SOFIE monitor the water vapour maximum at slightly higher altitudes than MIAWARA-C.

For Sodankylä10, no bias consistent for all instruments can be identified. ACE-FTS hints towards an almost constant wet bias of MIAWARA-C, whereas Aura MLS v3.3 hints towards a dry bias. The biases for Sodankylä11-13 are larger than for Sodankylä10, both towards the wet and towards the dry side. Currently, there is no explanation for the larger biases. SOFIE and MIPAS show strong oscillations in all data sets used. During the Zimmerwald campaigns MIAWARA-C seems to have a dry bias smaller than $5-12 \%$ for all altitudes above $45 \mathrm{~km}$ compared to MIAWARA and Aura MLS v3.3. MIAWARA is a ground-based instrument and was operating without any changes on the instrument. Therefore, the increase of the dry bias from a few percent for the correlation receiver to up to $12 \%$ with the dual-polarisation receiver is likely to be caused by the upgrade of MIAWARA-C. Taking the whole altitude range into account, the bias with respect to MIAWARA is oscillating around approximately $-1 \%$ for the old receiver setup and around $-6 \%$ for the new one. In addition, it increases with altitude. A similar behaviour is observed when comparing to both versions of Aura MLS; for Sodankylä the dual-polarisation receiver data are approximately $8 \%$ drier and for Zimmerwald the difference is approximately $3-7 \%$ depending on altitude.

The biases found are generally within $\pm 13 \%$ and are in most cases within the systematic error of MIAWARA-C. Hence, the estimated systematic error of MIAWARA-C has proven to be a conservative estimation. No systematic errors were taken into account for the satellite instruments. 


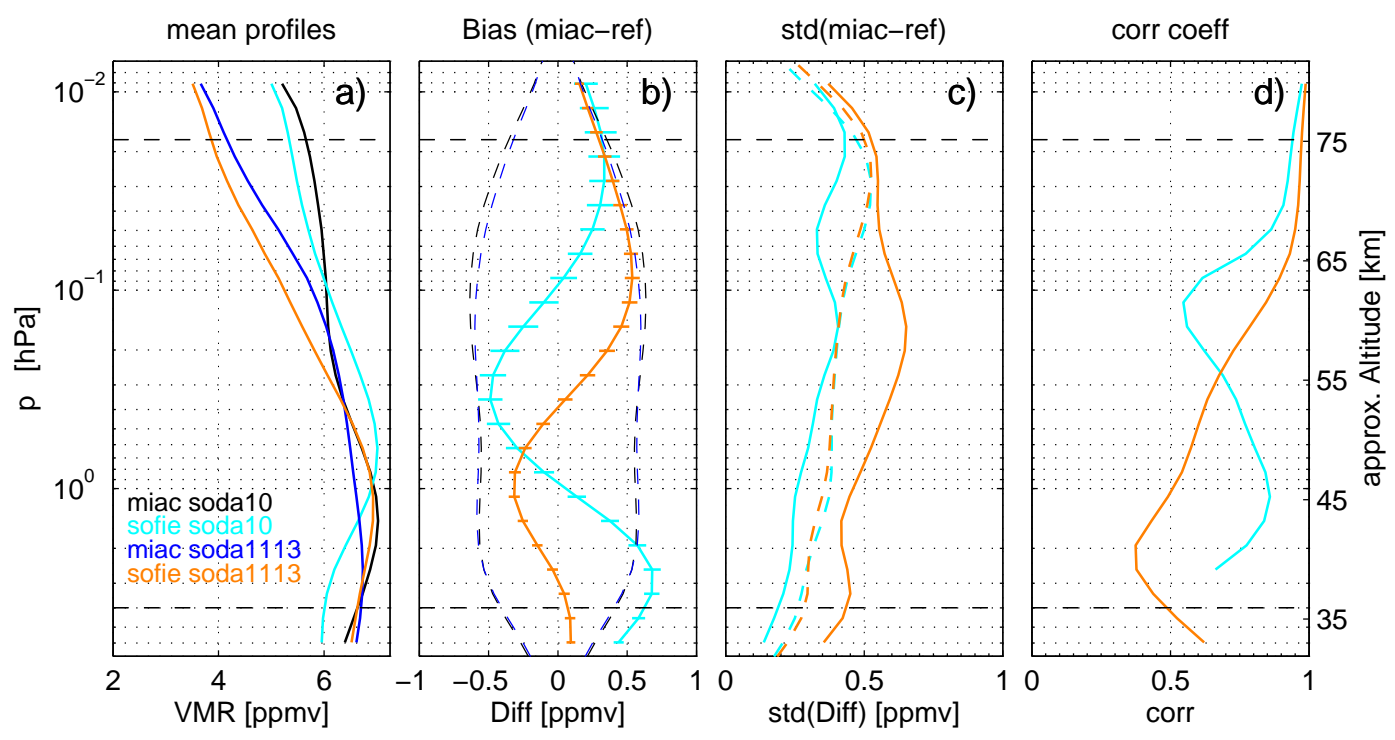

Fig. 14. Intercomparison MIAWARA-C - SOFIE for Sodankylä10 and Sodankylä11-13. (a) Mean coincident profiles of SOFIE (cyan)/MIAWARA-C (black) for 2010 and of SOFIE (orange)/MIAWARA-C (blue) for 2011-2013. (b) Bias (solid) and its standard error (horizontal) with for 2010 (cyan) and 2011-2013 (orange) together with the estimated systematic error of MIAWARA-C (black dashed for 2010, blue dashed for 2011-2013). (c) Standard deviation of differences (solid; cyan for 2010, orange for 2011-2013) and combined random error of the instruments (dashed). (d) Correlation coefficients (cyan for 2010, orange for 2011-2013). All plots use MIAWARA-C data with $\mathrm{AoA}>0.5$. The dashed horizontal lines indicate the reliable altitude range $(\mathrm{AoA}>0.8)$.

Therefore, the estimated systematic error of v1.1 is confirmed to be an upper limit.

The comparison of the combined random errors to the observed random variations shows good agreement using MIAWARA, Aura MLS and ACE-FTS data, allowing us for us to conclude that v1.1 random error estimates are realistic. The comparison with MIPAS hints towards an underestimation of the random errors below $0.1 \mathrm{hPa}$ of one or both of the instruments. In contrast, Stiller et al. (2012) found an overestimated combined random error by comparing two different versions of MIPAS and MIAWARA-C. When comparing to SOFIE, the observed and estimated random variations of the difference profiles agree throughout the whole altitude range for Sodankylä10 but indicate an underestimation of the estimated random error of one of the instruments for Sodankylä11-13. The source of these discrepancies is unclear.

The comparison to MIAWARA and ACE-FTS and most comparisons to Aura MLS show slightly larger observed variations below $45 \mathrm{~km}$ and around $70 \mathrm{~km}$. This discrepancy between estimated and observed variability around $70 \mathrm{~km}$ and below $45 \mathrm{~km}$ could be caused by contributions from natural variations due to non-optimal coincidence or by an underestimation of one of the instrument's random errors. Below approximately $45 \mathrm{~km}$, MIAWARA-C's contribution of the baseline to the random error might be underestimated. This error is included in the error budget via the random calibration uncertainty. Around $70 \mathrm{~km}$, the observed variability is larger than the combined estimated random error. Attributing this difference to an underestimation of MIAWARA-C's random error, it could originate from an underestimation of the influence of the spectral noise on the profile, underestimation of the a priori covariance matrix $\mathbf{S}_{\mathrm{a}}$ at these altitudes or from an underestimation of the random temperature uncertainty in MIAWARA-C's error budget. The variability observed by comparing profiles retrieved from the two polarisation channels of MIAWARA-C originates purely from spectral noise and is in excellent agreement with the estimated random measurement noise error of v1.1 (see Sect. 2.3).

The correlation coefficients for all reference instruments and for both campaigns are summarised in Fig. 16. All correlation coefficients of the coincident data sets displayed are significant at the $95 \%$ confidence level. The typical shape of a correlation profile shows high values above $45 \mathrm{~km}$, confirming the quality of MIAWARA-C's measured time series. Below $45 \mathrm{~km}$ the correlation coefficients decrease. This decrease is probably related to baseline effects in MIAWARAC's retrieval and the less pronounced seasonal cycle at these altitudes. Baseline effects add an uncorrelated signal to the time series and uncorrelated signals increase their contribution for decreasing correlated variations. For both Zimmerwald campaigns the correlation coefficients between MIPAS and MIAWARA-C are significant only for a few altitude levels, which is linked to the high observed random variation. Both for data measured with the correlation and with the dual-polarisation receiver of MIAWARA-C, the correlation is higher for Sodankylä than for Zimmerwald. The main reason is found in the larger variations of water vapour observed in the Arctic. 

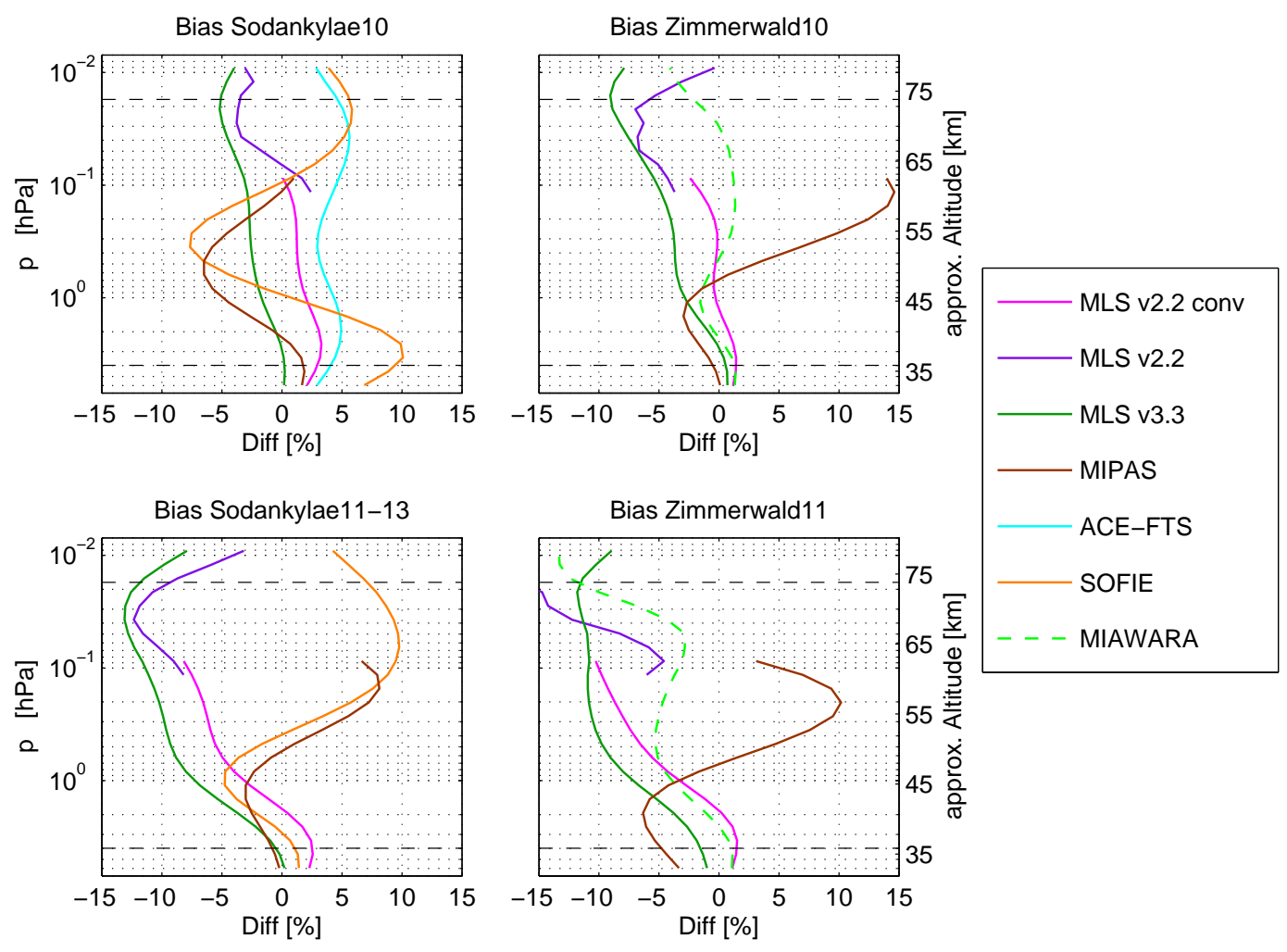

Fig. 15. Summary of all means of the differences relative to MIAWARA-C (bias) for both campaigns. All plots use MIAWARA-C data with $\mathrm{AoA}>0.5$. The dashed horizontal lines indicate the reliable altitude range $(\mathrm{AoA}>0.8)$.

\section{Conclusions}

The ground-based microwave radiometer MIAWARA-C for middle-atmospheric water vapour is operated on a campaign basis. The retrieval version 1.1 provides a consistent data set for all of MIAWARA-C's measurement sites to date. Water vapour profiles of v1.1 cover the altitude range from $4 \mathrm{hPa}$ $(37 \mathrm{~km})$ to $0.017 \mathrm{hPa}(75 \mathrm{~km})$. The dual-polarisation receiver of MIAWARA-C, upgraded in December 2010, offers the opportunity to compare the estimated measurement noise error to independent measurements of the two receiver channels. The estimated measurement noise error of v1.1 and the observed variability are in excellent agreement.

The quality of v1.1 is assessed for two receiver setups of MIAWARA-C using five months of measurements in the Arctic (LAPBIAT campaign), nine months of measurements at mid-latitudes (Zimmerwald) and a second campaign in the Arctic of 20 months. For both locations, the data are compared to Aura MLS and MIPAS. For Sodankylä, additional data measured by SOFIE are taken into account and for the first Sodankylä campaign data measured by ACEFTS are used as well. Zimmerwald data are compared to the ground-based radiometer MIAWARA. The spatial coincidence criterion applied in latitude is $+1^{\circ} /-2^{\circ}$ for Sodankylä and $+2^{\circ} /-1^{\circ}$ for Zimmerwald; in longitude it is $\pm 10^{\circ}$ for both locations. Only profile pairs with a maximum temporal difference of $12 \mathrm{~h}$ for the satellite instruments and $6 \mathrm{~h}$ for MIAWARA are considered.

In general, the biases found between MIAWARA-C and the reference instruments are within $\pm 13 \%$. The biases can be explained for most data sets used by the conservative estimation of MIAWARA-C's v1.1 systematic error proving it to be an upper limit. MIPAS is affected by non-LTE effects not yet included in the retrieval causing a known bias above $45 \mathrm{~km}$ (Stiller et al., 2012), and the comparison to SOFIE shows strong oscillation with altitude due to differences in the observed profile shapes. There is no consistent bias found for all reference instruments. However, for the Zimmerwald campaign, MIAWARA-C shows a dry bias above $45 \mathrm{~km}$ which is increasing with altitude. Comparing to MIAWARA and Aura MLS, the dry bias with the dualpolarisation receiver seems to be more pronounced by $3-8 \%$ than the one observed with the correlation receiver.

The estimated random error of MIAWARA-C is combined with the reference instruments precision and then compared to the standard deviation of the differences of the coincident measurements. Between $45 \mathrm{~km}$ and $70 \mathrm{~km}$ most estimated and observed random errors agree well, while MIPAS indicates an underestimation of the random error. The comparisons with MIAWARA, Aura MLS, MIPAS and ACE-FTS show two local maxima of observed random variation below $45 \mathrm{~km}$ and above $70 \mathrm{~km}$ which, for some comparison 

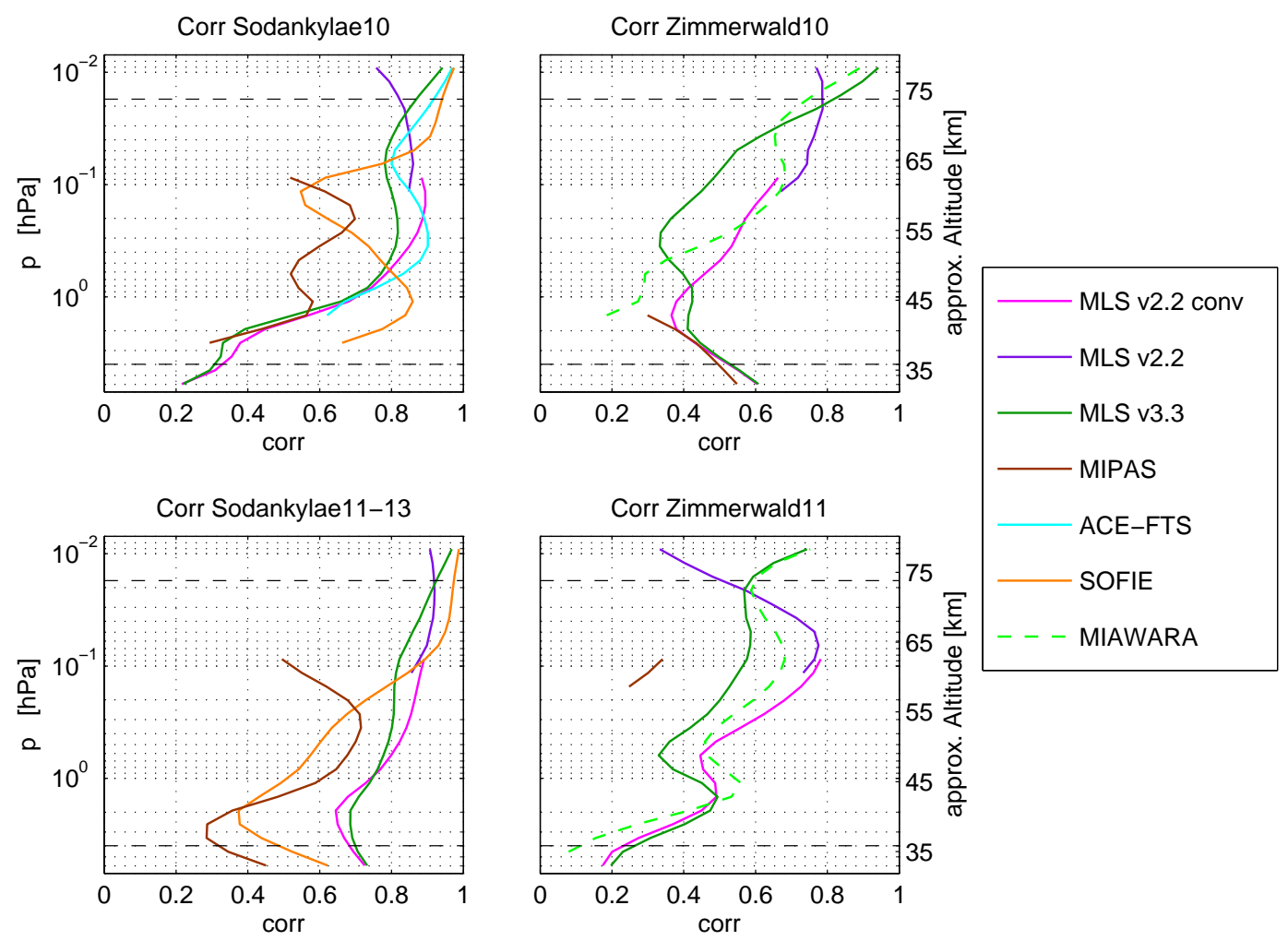

Fig. 16. Summary of all correlation coefficients for both campaigns. All plots use MIAWARA-C data with AoA >0.5. The dashed horizontal lines indicate the reliable altitude range $(\mathrm{AoA}>0.8)$.

data sets, hint towards an underestimation of the estimated random error. The difference at low altitudes is attributed to random effects originating from the spectral baseline fit in MIAWARA-C's retrieval which might be slightly underestimated in the error estimation. The source of the underestimation of MIAWARA-C's random error above $70 \mathrm{~km}$ might be due to underestimated random uncertainties of the temperature profile used for the retrieval and non-perfect coincidence.

The coincident satellite and ground-based measurements of water vapour used for this intercomparison study support the reliability of MIAWARA-C's v 1.1 for monitoring the temporal evolution of water vapour above the measurement site. The correlation coefficients of the coincident data sets are mostly significant at the $95 \%$ confidence level and are generally increasing with altitude. In the mesosphere most values are in the range from 0.6 to 0.97 . The observed correlation decreases towards lower altitude levels. The low correlation at low altitudes is partly attributed to random effects originating from the spectral baseline of MIAWARA-C and partly to only small seasonal variations.

MIAWARA-C's v1.1 has no major biases. In addition, the estimated random and systematic errors are confirmed to be realistic by this validation study. The demonstrated data quality emphasises the value of the measurements obtained with MIAWARA-C.
Acknowledgements. This work has been supported by the Swiss National Science Foundation grant number 200020-146388. Participation in the LAPBIAT campaign was funded through the Lapland Atmosphere-Biosphere Facility (LAPBIAT2), which is part of the EU Sixth Framework Programme. We thank the team of the Finnish Weather Service for their hospitality and support during the campaigns. We like to thank the Bern University Research Foundation for funding the weather station of MIAWARA-C. Assistance provided by the ARTS/Qpack team is greatly appreciated. The Atmospheric Chemistry Experiment (ACE), also known as SCISAT-1, is a Canadian-led mission mainly supported by the Canadian Space Agency and the Natural Sciences and Engineering Research Council of Canada. The provision of MIPAS level-1b data by ESA is gratefully acknowledged. We thank NASA for making Aura MLS data available. We thank the the NASA/AIM team for making SOFIE data available. We would like to thank AMT's production office and editorial support, the associate editor Bernd Funke, and the two anonymous referees for their work.

Edited by: B. Funke 


\section{References}

Bernath, P. F., McElroy, C. T., Abrams, M. C., Boone, C. D., Butler, M., Camy-Peyret, C., Carleer, M. R., Clerbaux, C., Coheur, P. F., Colin, R., DeCola, P., Bernath, P. F., McElroy, C. T., Abrams, M. C., Boone, C. D., Butler, M., Camy-Peyret, C., Carleer, M. R., Clerbaux, C., Coheur, P. F., Colin, R., DeCola, P., DeMaziere, M., Drummond, J. R., Dufour, D. G., Evans, W. F. J., Fast, H., Fussen, D., Gilbert, K., Jennings, D. E., Llewellyn, E. J., Lowe, R. P., Mahieu, E., McConnell, J. C., McHugh, M., McLeod, S. D., Michaud, R., Midwinter, C., Nassar, R., Nichitiu, F., Nowlan, C. R., Rinsland, C. P., Rochon, Y. J., Rowlands, N., Semeniuk, K., Simon, P., Skelton, R., Sloan, J. J., Soucy, M. A., Strong, K., Tremblay, P., Turnbull, D., Walker, K. A., Walkty, I., Wardle, D. A., Wehrle, V., Zander, R., and Zou, J.: Atmospheric Chemistry Experiment (ACE): Mission overview, Geophys. Res. Lett., 32, L15S01, doi:10.1029/2005GL022386, 2005.

Boone, C. D., Nassar, R., Walker, K. A., Rochon, Y., McLeod, S. D., Rinsland, C. P., and Bernath, P. F.: Retrievals for the atmospheric chemistry experiment Fourier-transform spectrometer, Appl. Optics, 44, 7218-7231, 2005.

Brasseur, G. P., Orlando, J. J., and Tyndall, G. S. (Eds.): Atmospheric Chemistry and Global Change, Oxford University Press, 1999.

Buehler, S. A., Eriksson, P., Kuhn, T., von Engeln, A., and Verdes, C.: ARTS, the atmospheric radiative transfer simulator, J. Quant. Spectrosc. Ra., 91, 65-93, doi:10.1016/j.jqsrt.2004.05.051, 2005.

Carleer, M. R., Boone, C. D., Walker, K. A., Bernath, P. F., Strong, K., Sica, R. J., Randall, C. E., Vömel, H., Kar, J., Höpfner, M., Milz, M., von Clarmann, T., Kivi, R., Valverde-Canossa, J., Sioris, C. E., Izawa, M. R. M., Dupuy, E., McElroy, C. T., Drummond, J. R., Nowlan, C. R., Zou, J., Nichitiu, F., Lossow, S., Urban, J., Murtagh, D., and Dufour, D. G.: Validation of water vapour profiles from the Atmospheric Chemistry Experiment (ACE), Atmos. Chem. Phys. Discuss., 8, 4499-4559, doi:10.5194/acpd-8-4499-2008, 2008.

De Wachter, E., Haefele, A., Kämpfer, N., Ka, S., Lee, J. E., and Oh, J. J.: The Seoul Water Vapor Radiometer for the Middle Atmosphere : Calibration, Retrieval, and Validation, IEEE T. Geosci. Remote, 49, 1052-1062, doi:10.1109/TGRS.2010.2072932, 2011.

Deuber, B., Kämpfer, N., and Feist, D. G.: A New 22$\mathrm{GHz}$ Radiometer for Middle Atmospheric Water Vapor Profile Measurements, IEEE T. Geosci. Remote, 42, 974-984, doi:10.1109/TGRS.2004.825581, 2004.

Eriksson, P., Jiménez, C., and Buehler, S. A.: Qpack, a general tool for instrument simulation and retrieval work, J. Quant. Spectrosc. Ra., 91, 47-64, doi:10.1016/j.jqsrt.2004.05.050, 2005.

Eriksson, P., Buehler, S. A., Davis, C., Emde, C., and Lemke, O.: ARTS, the atmospheric radiative transfer simulator, version 2, J. Quant. Spectrosc. Ra., 112, 1551-1558, doi:10.1016/j.jqsrt.2011.03.001, 2011.

Fischer, H., Birk, M., Blom, C., Carli, B., Carlotti, M., von Clarmann, T., Delbouille, L., Dudhia, A., Ehhalt, D., Endemann, M., Flaud, J. M., Gessner, R., Kleinert, A., Koopman, R., Langen, J., López-Puertas, M., Mosner, P., Nett, H., Oelhaf, H., Perron, G., Remedios, J., Ridolfi, M., Stiller, G., and Zander, R.: MIPAS: an instrument for atmospheric and climate research, Atmos. Chem. Phys., 8, 2151-2188, doi:10.5194/acp-8-2151-2008, 2008.
Gordley, L. L., Hervig, M. E., Fish, C., Russell III, J. M., Bailey, S., Cook, J., Hansen, S., Shumway, A., Paxton, G., Deaver, L., Marshall, T., Burton, J., Magill, B., Brown, C., Thompson, E., and Kemp, J.: The solar occultation for ice experiment, J. Atmos. Sol.-Terr. Phy., 71, 300-315, doi:10.1016/j.jastp.2008.07.012, 2009.

Haefele, A., De Wachter, E., Hocke, K., Kämpfer, N., Nedoluha, G. E., Gomez, R. M., Eriksson, P., Forkman, P., Lambert, A., and Schwartz, M. J.: Validation of ground-based microwave radiometers at $22 \mathrm{GHz}$ for stratospheric and mesospheric water vapor, J. Geophys. Res., 114, 1-11, doi:10.1029/2009JD011997, 2009.

Lambert, A., Read, W. G., Livesey, N. J., Santee, M. L., Manney, G. L., Froidevaux, L., Wu, D. L., Schwartz, M. J., Pumphrey, H. C., Jimenez, C., Nedoluha, G. E., Cofield, R. E., Cuddy, D. T., Daffer, W. H., Drouin, B. J., Fuller, R. A., Jarnot, R. F., Knosp, B. W., Pickett, H. M., Perun, V. S., Snyder, W. V., Stek, P. C., Thurstans, R. P., Wagner, P. A., Waters, J. W., Jucks, K. W., Toon, G. C., Stachnik, R. A., Bernath, P. F., Boone, C. D., Walker, K. A., Urban, J., Murtagh, D., Elkins, J. W., and Atlas, E.: Validation of the Aura Microwave Limb Sounder middle atmosphere water vapor and nitrous oxide measurements, J. Geophys. Res., 112, 1-24, doi:10.1029/2007JD008724, 2007.

Leblanc, T., Walsh, T. D., McDermid, I. S., Toon, G. C., Blavier, J.-F., Haines, B., Read, W. G., Herman, B., Fetzer, E., Sander, S., Pongetti, T., Whiteman, D. N., McGee, T. G., Twigg, L., Sumnicht, G., Venable, D., Calhoun, M., Dirisu, A., Hurst, D., Jordan, A., Hall, E., Miloshevich, L., Vömel, H., Straub, C., Kampfer, N., Nedoluha, G. E., Gomez, R. M., Holub, K., Gutman, S., Braun, J., Vanhove, T., Stiller, G., and Hauchecorne, A.: Measurements of Humidity in the Atmosphere and Validation Experiments (MOHAVE)-2009: overview of campaign operations and results, Atmos. Meas. Tech., 4, 2579-2605, doi:10.5194/amt-42579-2011, 2011.

Lee, J. N., Wu, D. L., Manney, G. L., Schwartz, M. J., Lambert, A., Livesey, N. J., Minschwaner, K. R., Pumphrey, H. C., and Read, W. G.: Aura Microwave Limb Sounder observations of the polar middle atmosphere: Dynamics and transport of $\mathrm{CO}$ and $\mathrm{H}_{2} \mathrm{O}$, J. Geophys. Res., 116, D05110, doi:10.1029/2010JD014608, 2011.

Liebe, H. J.: MPM - An atmospheric millimeter-wave propagation model, Int. J. Infrared. Millim., 10, 631-650, 1989.

Livesey, N. J., Read, W. G., Lambert, A., Cofield, R. E., Cuddy, D. T., Froidevaux, L., Fuller, R. A., Jarnot, R. F., Jiang, J. H., Jiang, Y. B., Knosp, B. W., Kovalenko, L. J., Pickett, H. M., Pumphrey, H. C., Santee, M., L., Schwartz, M. J., Stek, P. C., Wagner, P. A., Waters, J. W., and Wu, D. L.: Quality, Earth Observing System (EOS) Aura Microwave Limb Sounder (MLS) Version 2.2 Level 2 data quality and description document, Tech. rep., Jet Propulsion Laboratory, 2007.

Livesey, N. J., Read, W. G., Froidevaux, L., Lambert, A., Manney, G. L., Pumphrey, H. C., Santee, M. L., Schwartz, M. J., Wang, S., and Cof, R. E.: Earth Observing System (EOS) Aura Microwave Limb Sounder (MLS) Version 3.3 Level 2 data quality and description document, Tech. rep., Jet Propulsion Laboratory, 2011.

Lossow, S., Urban, J., Schmidt, H., Marsh, D. R., Gumbel, J., Eriksson, P., and Murtagh, D.: Wintertime water vapor in the polar upper mesosphere and lower thermosphere: First satellite observations by Odin submillimeter radiometer, J. Geophys. Res., 114, D10304, doi:10.1029/2008JD011462, 2009. 
Nedoluha, G. E., Gomez, R. M., Hicks, B. C., Helmboldt, J., Bevilacqua, R. M., and Lambert, A.: Ground-based microwave measurements of water vapor from the midstratosphere to the mesosphere, J. Geophys. Res., 116, 1-11, doi:10.1029/2010JD014728, 2011.

Poynter, R. L. and Pickett, M.: Submillimeter, millimeter, and microwave spectral line catalog, Appl. Optics, 24, 2235-2240, 1985.

Rodgers, C. D.: Inverse Methodes for Atmospheric Soundings, World Scientific Publishing Co. Pte. Ltd, Singapore, 2000.

Rong, P., Russell III, J. M., Gordley, L. L., Hervig, M. E., Deaver, L., Bernath, P. F., and Walker, K. A.: Validation of v1.022 mesospheric water vapor observed by the Solar Occultation for Ice Experiment instrument on the Aeronomy of Ice in the Mesosphere satellite, J. Geophys. Res., 115, 1-17, doi:10.1029/2010JD014269, 2010.

Scheiben, D., Straub, C., Hocke, K., Forkman, P., and Kämpfer, N.: Observations of middle atmospheric $\mathrm{H}_{2} \mathrm{O}$ and $\mathrm{O}_{3}$ during the 2010 major sudden stratospheric warming by a network of microwave radiometers, Atmos. Chem. Phys., 12, 7753-7765, doi:10.5194/acp-12-7753-2012, 2012.

Seele, C.: Bodengebundene Mikrowellenspektroskopie von Wasserdampf in der mittleren polaren Atmosphäre, Ph.D. thesis, University of Bonn, 1999.

Stiller, G. P., Kiefer, M., Eckert, E., von Clarmann, T., Kellmann, S., García-Comas, M., Funke, B., Leblanc, T., Fetzer, E., Froidevaux, L., Gomez, M., Hall, E., Hurst, D., Jordan, A., Kämpfer, N., Lambert, A., McDermid, I. S., McGee, T., Miloshevich, L., Nedoluha, G., Read, W., Schneider, M., Schwartz, M., Straub, C., Toon, G., Twigg, L. W., Walker, K., and Whiteman, D. N.: Validation of MIPAS IMK/IAA temperature, water vapor, and ozone profiles with MOHAVE-2009 campaign measurements, Atmos. Meas. Tech., 5, 289-320, doi:10.5194/amt-5-289-2012, 2012.
Straub, C., Murk, A., and Kämpfer, N.: MIAWARA-C, a new ground based water vapor radiometer for measurement campaigns, Atmos. Meas. Tech., 3, 1271-1285, doi:10.5194/amt-31271-2010, 2010.

Straub, C., Murk, A., Kämpfer, N., Golchert, S. H. W., Hochschild, G., Hallgren, K., and Hartogh, P.: ARIS-Campaign: intercomparison of three ground based $22 \mathrm{GHz}$ radiometers for middle atmospheric water vapor at the Zugspitze in winter 2009, Atmos. Meas. Tech., 4, 1979-1994, doi:10.5194/amt-4-1979-2011, 2011.

Straub, C., Tschanz, B., Hocke, K., Kämpfer, N., and Smith, A. K.: Transport of mesospheric $\mathrm{H}_{2} \mathrm{O}$ during and after the stratospheric sudden warming of January 2010: observation and simulation, Atmos. Chem. Phys., 12, 5413-5427, doi:10.5194/acp-12-54132012, 2012.

Waters, J. W., Froidevaux, L., Harwood, R. S., Jarnot, R. F., Pickett, H. M., Read, W. G., Siegel, P., Cofield, R. E., Filipiak, M., Flower, D., Holden, J., Lau, G. K., Livesey, N. J., Manney, G. L., Pumphrey, H., Santee, M. L., Wu, D. L., Cuddy, D. T., Lay, R. R., Loo, M., Perun, V. S., Schwartz, M. J., Stek, P. C., Thurstans, R. P., Boyles, M., Chandra, S., Chavez, M., Chen, G.-S., Chudasama, B., Dodge, R., Fuller, R. A., Girard, M., Jiang, J. H., Jiang, Y. B., Knosp, B. W., LaBelle, R. C., Lam, J., Lee, K. A., Miller, D., Oswald, J. E., Patel, N., Pukala, D., Quintero, O., Scaff, D., Snyder, W. V., Tope, M., Wagner, P. A., and Walch, M.: The Earth Observing System Microwave Limb Sounder (EOS MLS) on the Aura satellite, IEEE T. Geosci. Remote, 44, 10751092, doi:10.1109/TGRS.2006.873771, 2006. 